\title{
NATURALEZA DEL FENÓMENO CONTRACTUAL ELECTRÓNICO DESDE UNA PERSPECTIVA DOCUMENTAL: UN LASTRE HEREDADO
}

\author{
CONTRACTUAL NATURE OF THE ELECTRONIC \\ PHENOMENON FROM A DOCUMENTAL PERSPECTIVE: \\ AN INHERITED ENCUMBRANCE
}

\author{
JUAN FRANCISCO RODRÍGUEZ AYUSO*
}

Recibido: 31/03/2017

Aceptado: 20/05/2017

\begin{abstract}
SUMARIO: I. INTRODUCCIÓN. II. SOCIEDAD Y DERECHO COMO FENÓMENOS, YA, INSEPARABLES. 1. SERVICIOS DE LA SOCIEDAD DE LA INFORMACIÓN EN EL ORDENAMIENTO JURÍDICO ESPAÑOL: MARCO NORMATIVO REGULADOR. 2. CONCEPTO Y CARACTERES: SERVICIOS DE LA SOCIEDAD DE LA INFORMACIÓN COMO CONCEPTO GENERAL AGLUTINADOR DE FIGURAS HETEROGÉNEAS. III. LA NOCIÓN DE DOCUMENTO EN EL ÁMBITO DE LA CONTRATACIÓN ELECTRÓNICA. 1. TEORÍA DUALISTA TRADICIONAL EN TORNO AL DOCUMENTO: MISMOS PROBLEMAS, DISTINTO ENFOQUE. 2. NUEVA PROPUESTA: LA TEORÍA DEL DOCUMENTO COMO PALABRA Y EL PRINCIPIO DE EQUIVALENCIA FUNCIONAL COMO INSTRUMENTO REPARADOR QUE HA DE SER REELABORADO. 3. ELEMENTOS ESENCIALES Y CLASIFICACIÓN DEL DOCUMENTO EN SU CONCEPCIÓN ACTUAL. IV. BIBLIOGRAFÍA.
\end{abstract}

SUMMARY: I. INTRODUCTION. II. SOCIETY AND LAW AS INSEPARABLE PHENOMENA NOWADAYS. 1. SERVICES OF SOCIETY'S INFORMATION WITHIN THE SPANISH LEGAL SYSTEM: REGULATING LEGAL FRAMEWORK. 2. CONCEPT AND CHARACTERS: SERVICES OF SOCIETY'S INFORMATION AS THE COHESIVE GENERAL CONCEPT OF HETEROGENEOUS FIGURES. III. THE NOTION OF THE DOCUMENT WITHIN THE SCOPE OF THE ELECTRONIC CONTRACTING. 1. TRADITIONAL DUAL THEORY ABOUT THE DOCUMENT: SAME PROBLEMS, DIFFERENT APPROACHES. 2. NEW PROPOSAL: THE THEORY OF THE DOCUMENT AS WORD AND THE PRINCIPLE OF FUNCTIONAL EQUIVALENCE AS A BETTERMENT TOOL WHICH HAS TO BE RE-ELABORATED. 3. ESSENTIAL ELEMENTS AND DOCUMENT CLASSIFICATION IN ITS ACTUAL CONCEPTION. IV. BIBLIOGRAPHY.

Resumen: El objetivo principal del presente trabajo consiste en ofrecer un análisis sistemático de la aplicación de las modernas tecnologías de la información y de la comunicación en los procedimientos de contratación electrónica y en los medios de prueba derivados del incumplimiento de las obligaciones contraídas al amparo de la misma. En concreto, se exponen sintetizadamente las principales posturas existentes en torno a la consideración del documento electrónico como medio de prueba y una propuesta de lege ferenda que contemple el contrato electrónico como auténtica prueba documental, subsanando la antinomia legislativa existente entre la ley procesal civil y la regulatoria de los servicios de la sociedad de la información. Por último, se expone cómo el principio de equivalencia funcional trata de subsanar este error heredado merced a una más que discutida redacción.

\footnotetext{
*Dottorando di Scienze Giuridiche nell’Università di Bologna. E-mail: juan.rodriguezayuso2@unibo.it. 
Palabras claves: contratación electrónica, servicios de la sociedad de la información, prueba documental, documento electrónico, principio de equivalencia funcional.

\begin{abstract}
The primary aim of the present work is to provide a systematic analysis of the application of modern information and communication technologies in electronic contract procedures and in the testing means derived from non-compliance with the undertaken obligations. Specifically, I note the main existing postures that consider the electronic document as a means of proof. I propose a lege ferenda that would contemplate the electronic contract as an authentic documentary evidence, correcting the legislative antinomy existing between the civil procedural law and the regulatory law of information society services. Finally, I expose how the principle of functional equivalence tries to correct this inherited error derived from a long-questioned wording.
\end{abstract}

Keywords: Electronic contract, information society services, documentary evidence, electronic document, principle of functional equivalence.

\title{
I. INTRODUCCIÓN
}

El desarrollo y la difusión exponencial de las nuevas tecnologías de la información y de la comunicación ha incidido en múltiples aspectos de la vida económica, política, cultural y jurídica, redefiniendo los conceptos de espacio, identidad y tiempo y propiciando una evolución en la conformación de la sociedad hacia formas hasta no hace mucho tiempo desconocidas e inimaginables. De manera evidente, este radical avance está favoreciendo un modelo de vida caracterizado, en esencia, por el constante incremento de la comunicación a distancia y la extraordinaria rapidez en la transmisión de la información, protagonista fundamental de esta nueva etapa que se abre espacio. Experimentamos, de este modo, el tránsito de la vetusta sociedad industrial o postindustrial a la incipiente sociedad de la información ${ }^{1}$, nuevo paradigma de carácter socio-tecnológico en el que los bienes más preciados no serán, ya, los materiales.

En esta nueva era de la información, la Red define la morfología social y constituye la base material de los nuevos fenómenos culturales (cultura de la realidad virtual) y económicos (la economía de la información global) que en la colectividad se suceden. Ahora, el poder se extiende, bifurca y desplaza de las instituciones y de las organizaciones hacia los sistemas globales de información, que circulan y mutan en un

\footnotetext{
${ }^{1}$ Como nítidamente expone SARTOR, G., L'informatica giuridica e le tecnologie dell'informazione: corso d’informatica giuridica, Giappichelli, Turín, 2012, p. 1, de la misma manera que la industrialización (el empleo de las máquinas en la elaboración de la materia) supuso el paso de la sociedad agrícola a la sociedad industrial, la informatización (el empleo de las máquinas en la elaboración de la información) está determinando la formación de la sociedad de la información o sociedad informacional.
}

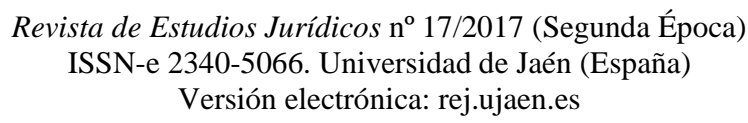


sistema de geometría variable y geografía desmaterializada ${ }^{2}$. Emerge, en definitiva, una nueva sociedad caracterizada por la centralidad y accesibilidad en masa del saber (proceso que genera, a su vez, una suerte de inteligencia colectiva) y por el predominio de la interacción comunicacional en forma virtual a través de lo que conocemos como ciberespacio, la nueva casa de la mente ${ }^{3}$. A partir de este momento, como diría LÉVY ${ }^{4}$, la técnica propone y el hombre dispone.

Las principales ventajas (algunas ya apuntadas) que trae consigo este fenómeno parecen, en la actualidad, evidentes: gracias a él, ciudadanos de todo el mundo pueden acceder desde cualquier punto o terminal y en cualquier momento a información y documentación, actual o pretérita, sita a miles de kilómetros, desde su asiento y sin necesidad de desplazarse, con el consiguiente ahorro temporal y económico que ello supone $^{5}$. Asimismo, se produce una apertura extraordinaria de las posibilidades de comunicación con otras personas e instituciones a escala internacional, sin limitación cuantitativa de ningún tipo, sectorial o espacial ${ }^{6}$. Y todo esto acompañado del

\footnotetext{
${ }^{2}$ CAstells Oliván, M., The power of identity, Wiley-Blackwell, Oxford, 2010, p. 30.

${ }^{3}$ BARLOW, J. P., “A declaration of the independence of cyberspace”, 1996, Davos. Definido por la RAE como «ámbito artificial creado por medios informáticos», este término fue popularizado a raíz de la novela de GIBSON, W., Neuromancer, Ace Books, Nueva York, 1984, si bien su origen se encuentra en el relato, también de GIBSON, W., Johnny Mnemonic, Ace Books, Nueva York, 1982, incluido en el volumen Burning Chrome. Sobre esta cuestión y los aspectos críticos que conlleva su conciliación con el mundo jurídico, Vid. CaBanellas De las Cuevas, G., Derecho de Internet, Elisa, Buenos Aires, 2012, pp. 71 a 85, que niega la existencia de un Derecho especial para el ciberespacio, reducido a la existencia de cuestiones jurídicas específicas que deberían ser solucionadas desde la perspectiva de los principios generales en la materia (propiedad intelectual, contratos, etc.) o Di Cocco,C./SARTOR, G., Temi di Diritto dell'informatica, Giappichelli, Turín, 2013, p. 1, quienes se hacen eco de la concepción de este mundo virtual como un espacio dotado de cultura y ética propias que, por esa misma razón, no tiene necesidad de política y de Derecho, siendo capaz de autorregularse y de resolver sus propios conflictos con sus propios medios.

${ }^{4}$ LÉvY, P., Qu'est-ce que le virtuel?, La Découverte, París, 1998, p. 141.

${ }^{5}$ De Miguel Asensio, P. A., Contratación electrónica, Aranzadi, Cizur Menor, 2015, pp. 33 y 34. Conviene precisar, no obstante, el distinto nivel de acceso que a este desarrollo tecnológico se produce entre regiones económicamente más y menos favorecidas, originando una importante discriminación de partida. Así es, la distinta participación en este nuevo modelo social no hace sino acrecentar, en principio, las desigualdades entre inforricos (con posibilidades de conexión) e infopobres (en situación de desconexión), que hace a algunos autores hablar, incluso, de «apartheid digital»; entre ellos se encuentra Moliní FERnÁNDEZ, F., "Ventajas, inconvenientes e impactos territoriales del comercio electrónico", Investigaciones geográficas, n. 27, 2002, p. 143, quien añade, no obstante, que es muy probable que no haya existido hasta ahora un espacio tan global y con menor discriminación por motivos de raza, nacionalidad, sexo, religión o de cualquier otro tipo. Para un estudio más profundo de esta cuestión, Vid., entre otros, AMAR RoDríguez, V. M., "La interculturalidad tecnológica: inforricos e infopobres”, en Inmigración, interculturalidad y convivencia, Instituto de Estudios Ceutíes, Ceuta, 2002.

${ }^{6}$ SANJURJo ReBOllo, B., Manual de Internet y redes sociales: una mirada legal al nuevo panorama de las comunicaciones en la Red, con especial referencia al periodismo digital, propiedad intelectual, protección de datos, negocios audiovisuales, e-commerce, consumidores, marketing, Dykinson, Madrid, 2015, p. 34.
} 
nacimiento de novedosas y originales oportunidades de entretenimiento surgidas al albor de esta nueva cultura cibernética ${ }^{7}$.

Desde una perspectiva puramente mercantil, la aplicación de estas modernas tecnologías a la actividad económica, más específicamente a aquella que tiene lugar como forma de intermediación entre la producción, de un lado, y el consumo, de otro, origina el nacimiento de una modalidad de comercio, distinto y alternativo (que no incompatible) del comercio tradicional y que ha dado en conocerse como comercio electrónico ${ }^{8}$. Los beneficios que se anudan a estos cambios no son tampoco desdeñables, ni por extensión ni por intensidad. Para el consumidor o usuario, la implementación de este desarrollo tecnológico permite el acceso a un mayor número de bienes y servicios. Ello, unido a la reducción para los productores de aquellos costes derivados de la eliminación de intermediarios ${ }^{9}$ y la sustitución de una infraestructura física por una de carácter virtual sin necesidad de almacenamiento material, permite al comprador la obtención de mejores (más baratos) precios. También posibilita un mayor y más fácil acceso a información relativa a las características de los bienes y servicios ofertados, una mejora en la calidad de los mismos, una mayor personalización (las ofertas se encuentran más ajustadas a las necesidades de los clientes), un sustancial incremento del poder negociador merced a la creación de las comunidades virtuales ${ }^{10} \mathrm{y}$ una minoración, en fin, del tiempo empleado para efectuar la adquisición, al facilitarse la comparación simultánea de precios, condiciones y características. Para el vendedor o empresario, este traslado del escenario de venta de la calle al ordenador ${ }^{11}$ permite saber más acerca de los competidores gracias al aprendizaje organizativo, al tiempo que posibilita una mayúscula apertura de las oportunidades de negocio, toda vez que los potenciales clientes a los que ahora puede acceder se multiplican de manera

\footnotetext{
${ }^{7}$ Bravo, F., Contrattazione telematica e contrattazione cibernetica, Giuffrè, Milán, 2007, p. 625; Miranda Serrano, L. M./Vela Torres, P. J./Príes PicArdo, A., La contratación mercantil. Disposiciones generales. Protección de los consumidores, Marcial Pons, Madrid, 2006, p. 336.

${ }^{8}$ Ibid., p. 336.

${ }^{9}$ Con la aparición del comercio electrónico, la importancia de los intermediarios (mayoristas y minoristas) se reduce, ya que se facilita y favorece el contacto entre productores y consumidores. De igual modo, cualquiera de los intermediarios puede relacionarse con el consumidor final, haciendo innecesarios el resto de eslabones de la cadena tradicional. Cierto es, no obstante, que con la aparición y expansión del comercio electrónico también aparecen nuevos intermediarios hasta ahora desconocidos. Para un estudio más profundo de cuanto acabamos de citar, Vid. BotAnA GARCíA, G. A., Comercio electrónico y protección de los consumidores, Wolters Kluwer, Las Rozas, 2001, pp. 92 y 93, 104.

${ }^{10}$ Las comunidades virtuales hacen referencia a aquellos grupos de personas dotados de cierta estabilidad que se hallan conectados entre sí en línea y someten a discusión uno o varios aspectos cuyo interés es compartido por todos ellos, pudiendo ejercer presión conjunta a fin de alcanzar un objetivo común en materia comercial. De este asunto trata de manera tanto más profunda CARRETERo PÉREZ, J., Descubre Internet, Prentice Hall, Madrid, 2001, p. 121 y SÁBADA CHALEZQUER, C., "Interactividad y comunidades virtuales en el entorno de la world wide web”, Comunicación y sociedad, n. 1, 2000, pp. 139 a 166.

${ }^{11}$ Varias han sido las respuestas adoptadas frente a este nuevo reto: algunas empresas han optado por la sustitución del establecimiento material tradicional en el que surgieron por un modelo de negocio entera y exclusivamente virtual o telemático. Otras, en cambio, han preferido complementar ambos tipos de mercados, permaneciendo abiertas al público de un modo físico pero sirviéndose, al mismo tiempo, de estos nuevos instrumentos para potenciar el volumen de sus ventas. Por último, se encuentran aquellas empresas que nacen unidas a esta nueva cultura (las conocidas como empresas puntocom).
} 
extraordinaria, favoreciendo, asimismo, una mayor celeridad en el desarrollo de relaciones comerciales y el poder de competir en pie de igualdad con estructuras y organizaciones superiores en tamaño ${ }^{12}$.

Ahora bien, como es lógico, nunca todo cambio es enteramente positivo. La inmaterialidad de estos procesos origina desconfianza en el usuario, ávido de una respuesta legal acorde a la trascendencia de los cambios. Así, cuestiones tales como la identificación de la contraparte, la falta de verificación en el momento de efectuar la adquisición del estado y características reales del producto o servicio ${ }^{13}$, la incertidumbre acerca de la validez y eficacia de las transacciones que se producen vía electrónica o el desarrollo de prácticas de comercialización no solicitadas y engañosas obstaculizan, a menudo, el desarrollo integral de esta nueva modalidad electrónica. Similar efecto produce el empleo generalizado de los contratos de adhesión, la imposición de cláusulas contractuales abusivas, la posibilidad de tramitar pedidos mediante simple pulsación de teclas, la distribución de riesgos y la delimitación de responsabilidades entre los distintos sujetos intervinientes, el diseño de páginas web que favorecen declaraciones negociales impulsivas ${ }^{14}$, la dificultad para determinar la ley y jurisdicción aplicables en caso de litigio como consecuencia de la naturaleza transfronteriza tradicionalmente anudada a este tipo de comercio, la complejidad que supone el acceso en condiciones óptimas de seguridad a servicios en línea públicos y privados o, en fin, los problemas derivados de la perfección y prueba de los contratos celebrados por este medio ${ }^{15}$. Con base en este último problema, en el presente trabajo se exponen los principales obstáculos legales existentes en torno a la prueba del documento electrónico y, como vertiente principal dentro del mismo, del contrato celebrado en forma telemática.

\section{SOCIEDAD Y DERECHO COMO FENÓMENOS, YA, INSEPARABLES}

\footnotetext{
${ }^{12}$ DíAz Fraile, J. M., "El comercio electrónico: Directiva y Proyecto de Ley español de 2000. Crónica de su contenido, origen, propósitos y proceso de elaboración”, Actualidad civil, n. 1, 2001, p. 43; MoLiNí FERNÁNDEZ, F., "Ventajas, inconvenientes e impactos territoriales del comercio electrónico”, cit., pp. 142 a 144; Shaw, M./Blanning, R./Strader, T./Whinston, A., Handbook on Electronic Commerce, Springer, Berlín, 2000, pp. 19 a 21.

${ }^{13}$ De Miguel Asensio, P. A., Contratación electrónica, cit., pp. 33 y 34.

${ }^{14}$ La configuración y el diseño de páginas web dedicadas al negocio con consumidores es fundamental para garantizar la tutela de estos. Para ello, es fundamental que se adopten medidas en materia de información, sobre el negocio (identificación, localización, datos de contacto, de registro, códigos de conducta, sistemas de certificación o mecanismos de solución de controversias), sobre las características de los productos y servicios ofertados o sobre las transacciones que tengan lugar (idioma empleado, condiciones generales, coste exacto, condiciones y puesta a disposición, pago, tiempo de entrega, seguridad, servicio postventa, revocación, terminación, derecho de desistimiento o garantías). Además, y para reforzar la decisión consciente del adquirente, es importante que se permita a este, antes de concluir la compra, la posibilidad de identificar con claridad los bienes y/o servicios que se desean adquirir, de rectificar el pedido, de manifestar su aceptación final y de obtener un recibo de la operación realizada.

${ }^{15}$ Rosello, C., Commercio elettronico: la governance di Internet tra Diritto statuale, autodisciplina, soft Law e lex mercatoria, Giuffrè, Milán, 2006, pp. 3 y 4; STOLL, P. T./GOLLER, B., Electronic commerce and the Internet, German Yearbook of International Law, Berlín, 1998, p. 162.
} 
El advenimiento de la sociedad de la información comporta múltiples y sustanciales transformaciones sociales que, a su vez, generan nuevas exigencias, nuevos intereses y nuevos conflictos que requieren de disciplina jurídica. Vamos conformando paulatinamente un panorama general que, analizado si quiera mínima o someramente, plantea serios problemas ávidos de respuestas adecuadas y acordes a la seguridad que los sujetos de derechos y obligaciones, principales afectados por las incidencias de las nuevas tecnologías, necesitan para desenvolverse con suficiente confianza y de manera adecuada en un mundo virtual cada vez más inmerso en nuestra cotidianeidad. De esta manera, la regulación de la Red por el Derecho (o, lo que es lo mismo, la influencia del espacio digital en el ámbito jurídico, y viceversa) viene exigida por la peculiar naturaleza del medio técnico utilizado y requiere (se traduce) de (en) la adecuada combinación del Derecho tradicional con un Derecho nuevo, necesarios, ambos, en un contexto global que, caracterizado por la creciente diversidad y la eclosión de importantes intereses comerciales, amenaza los valores de libertad, apertura y cooperación que caracterizaron los inicios de su proceso ${ }^{16}$.

Como Derecho tradicional, el nuevo contexto planteará una problemática jurídica hasta el momento desconocida, propiciada, en esencia, por la desaparición del papel y de la firma manuscrita para el desenvolvimiento de relaciones negociales ${ }^{17}$, cuestión que, de manera inexorable, desembocará en una revisión del viejo Derecho, es decir, del negocio jurídico, de las declaraciones de voluntad, del documento, de la autenticidad y la autenticación de la firma, de la prueba o de la seguridad jurídica en el tráfico (postura instrumental) ${ }^{18}$. Podemos afirmar, en consecuencia, que uno de los principales obstáculos que puede dificultar la expansión, primero, y consolidación, después, del modelo virtual se encuentra en la inadecuación de las vetustas fórmulas jurídicas para solucionar muchos de los problemas que conlleva el mundo digital, o, lo que es lo mismo, en la improcedencia de aplicar conceptos y categorías clásicas a transacciones comerciales que ya no lo son ${ }^{19}$. Esta circunstancia motiva la intervención del legislador para adoptar medidas legislativas que resulten adecuadas en orden a remediar,

\footnotetext{
${ }^{16}$ Di CoccoC./SARTOR, G., Temi di Diritto dell'informatica, cit., p. 19.

${ }^{17}$ MARTíNEZ NADAL, A., "La protección del consumidor en la propuesta de directiva sobre determinados aspectos del comercio electrónico”, Cuadernos de Derecho y comercio, n. 29, 1999, p. 114; MARTÍNEZ NADAL, A., "Comercio electrónico”, en Curso sobre protección jurídica de los consumidores, McGrawHill, Madrid, 1999, pp. 247 y ss.; MADRID PARRA, A., “Contratación electrónica”, en Estudios jurídicos en homenaje al profesor Aurelio Menéndez, Civitas, Madrid, 1996, p. 2941. En términos similares tuvo ocasión de pronunciarse la STS de 3 de noviembre de 1997 [TOL2.506.500], que afirmaba que «estamos asistiendo, en cierto modo, en algunas facetas de la vida, incluso jurídica, al ocaso de la civilización del papel, de la firma manuscrita y del monopolio de la escritura sobre la realidad documental. El documento, como objeto corporal que refleja una realidad fáctica con trascendencia jurídica, no puede identificarse, ya, en exclusiva, con el papel, como soporte, ni con la escritura, como unidad de significación. El ordenador y los ficheros que en él se almacenan constituyen, hoy día, una nueva forma de entender la materialidad de los títulos valores y, en especial, de los documentos mercantiles».

${ }^{18}$ Miranda Serrano, L. M., Y OTROS, La contratación mercantil. Disposiciones generales. Protección de los consumidores, cit., p. 337.

${ }^{19}$ OLIVEnCia Ruiz, M., "De nuevo la Lección 1. . . Sobre el concepto de la asignatura. Discurso leído en la solemne apertura del curso académico”, 1999, Universidad de Sevilla.
} 
repetimos, muchas de las soluciones propuestas por el antiguo orden legal, adecuándolas a la realidad jurídica que ahora se nos plantea. El fin último que con esto se persigue no es otro que el de generar la confianza necesaria en los sujetos participantes para poder llevar a cabo operaciones jurídicas y económicas a través de estos modernos canales con una seguridad y eficiencia equiparables, en definitiva, a las existentes en el entorno físico ${ }^{20}$. Necesario será, por tanto, adaptar analógicamente (muchas veces por medio de la figura de la remisión) las vetustas estructuras y los sectores jurídicos tradicionales (Derecho privado, Derecho administrativo, Derecho penal o Derecho procesal, entre otros) a los cambios introducidos por las modernas tecnologías de la información y de la comunicación. Es el caso, entre otros, del comercio electrónico, que, salvo el cauce en el que se lleva a cabo, no presenta novedad alguna respecto del comercio tradicional, pudiendo ser reconducido a este para resolver toda problemática jurídica (en materia de publicidad, oferta o ejecución del contrato que, en su caso, se celebre) que pueda suscitar su ejercicio por vía telemática ${ }^{21}$.

Como Derecho nuevo, en muchos de los casos, dar respuesta a los cambios resulta imposible si estos no se ven acompañados de una paralela aparición e incorporación de sistemas y sectores hasta ahora desconocidos y, hasta cierto punto, inimaginables (postura ontológica). Estos cambios no tienen que ver con la naturaleza de la relación, sino con la naturaleza técnica del medio empleado, en particular su carácter global, inmaterial y deslocalizado ${ }^{22}$. A veces, el medio técnico creará problemas jurídicos del todo nuevos, relativos a la existencia misma de la Red y a su modo de funcionamiento, mientras que, otras veces, atribuirá una connotación fáctica distinta a problemas jurídicos conocidos, como sucede con ciertos ilícitos que pueden ser más fácilmente cometidos en el medio virtual y cuyas consecuencias resultan amplificadas; en este último caso, la norma existe ya, pero será necesario proceder a adaptarla para poder hacer frente a los nuevos desafíos que se presentan ${ }^{23}$.

\footnotetext{
${ }^{20}$ CAVANillas MúgicA, S., "Dieciocho recomendaciones para la empresa que practique comercio electrónico con consumidores”, Actualidad informática Aranzadi: revista de informática para juristas, $\mathrm{n}$. 37, 2000, p. 1; GUERRERO ClAVIJO, R., "Novedades en materia de contratación mercantil introducidas por la Ley de Servicios de la Sociedad de la Información”, CEFLegal: revista práctica de derecho. Comentarios y casos prácticos, n. 47, 2004, p. 6; JimÉneZ DE PARGA CABRERA, R., "El comercio electrónico ¿̇seguridad jurídica?”, Derecho de los negocios, n. 118 y 119, 2000, pp. 3 a 12.

${ }^{21}$ FinocChiARO, G. D./Delfini, F., Diritto dell'informatica, Utet Giuridica, Milanofiori Assago, 2007, p. 30.

${ }^{22}$ Tradicionalmente, como bien señala LORENZETTI, R., Comercio electrónico: documento, firma digital, contratos, daños, defensa del consumidor, Abeledo-Perrot, Buenos Aires, 2001, p. 37, ambas posturas han estado enfrentadas, surgiendo dos posiciones (las ya mencionadas postura instrumental -LEMLEY, M. A./LESSIG, L., The end of end-to-end: preserving the architecture of the Internet in the broadband, Ucla Law Review, Los Ángeles, 2000, p. 930; MUÑOz MACHADO, S., La regulación de la Red: poder y Derecho en Internet, Taurus, Barcelona, 2000, p. 36; TROTTER HARDY, I., "The proper legal regime for 'cyberspace'”, University of Pittsburgh Law Review, n. 55, 1994, pp. 994 y 995- y postura ontológica BOWReY, K., Law \& Internet cultures, Cambridge University Press, Cambridge, 2005, p. 45; PASCuZzI, G., Il Diritto dell'era digitale, Il Mulino, Bolonia, 2006, pp. 22-) que, yo, entiendo compatibles.

${ }^{23}$ BARIATTI, S., "Internet: aspects rélatifs aux conflits de lois", Rivista di Diritto internazionale privato $e$ processuale, n. 550, 1997, p. 550.
} 
Consecuencia de todo lo anterior, vemos que la conocida como informática jurídica, en cuanto disciplina unitaria, viene a bifurcarse en dos direcciones distintas: de una parte, la del Derecho de la informática, centrada en analizar y tratar de resolver los problemas jurídicos planteados por la informática (informática legislativa, judicial, administrativa y profesional) y en la que, por primera vez en la historia, el Derecho se hace dependiente de otra disciplina (la informática) para poder regular adecuadamente los acontecimientos sociales. De otra, la informática del Derecho, que estudia la utilización de la informática en el Derecho (en esencia, propiedad intelectual, protección de datos, documentos electrónicos, presencia virtual, comercio electrónico, gobierno electrónico, ciberdelincuencia o adecuación de la informática a los parámetros y exigencias constitucionales). Ambos, caras de una misma moneda, han conocido una enorme expansión en el curso de los últimos años, articulándose en sectores diversos que, en conjunto, han posibilitado de manera creciente el uso de las nuevas tecnologías como plasmación y realización de los derechos individuales y de las exigencias sociales ${ }^{24}$.

Es esta afirmación la que me lleva a la consideración, contrariamente a lo que pueda afirmar parte de la doctrina ${ }^{25}$, de que estamos en presencia de un Derecho de carácter horizontal o transversal (si bien también especializado), que extiende y prolonga sus efectos sobre la práctica totalidad de ramas o vertientes jurídicas, precisamente como manifestación del efecto expansivo del que surge y al que acompaña: Internet. Además, la rapidez de los cambios exige una paralela celeridad (no siempre posible) de la producción normativa, imprimiendo unos ritmos cada vez más acelerados para poder estar actualizados ${ }^{26}$. Ello nos recuerda a lo que, ya en la primera mitad del siglo XX (1946), Carl Schmitt denominó legislación motorizada, describiendo el fenómeno caracterizado por la incontenible y frenética multiplicación y alteración que sufrían las leyes en los ordenamientos jurídicos contemporáneos, denuncia que fue reiterada con posterioridad (1953) por Ortega y Gasset ${ }^{27}$.

Estamos, en definitiva, fruto del proceso globalizador que trae consigo la aparición de Internet como instrumento esencial del que se sirve la sociedad de la información, en presencia de un auténtico Derecho con vocación global, también conocido como lex informatica $^{28}$, propiciado, en gran parte, por su dimensión internacional y por la

\footnotetext{
${ }^{24}$ Para un estudio más pormenorizado de las relaciones entre Informática y Derecho a lo largo de estos años, Vid. SARTOR, G., L'informatica giuridica e le tecnologie dell'informazione: corso d'informatica giuridica, cit., pp. 16 a 41.

${ }^{25}$ Entre ellos, PÉREz BES, F., El Derecho de Internet, Atelier, Barcelona, 2016, pp. 23 y 24.

${ }^{26}$ Di Cocco, C./SARTOR, G., Temi di Diritto dell'informatica, cit., pp. 22 a 24.

27 Ambos autores son mencionados, al hilo de esta cuestión, en la obra de GARCía DE ENTERRÍA MARTínEZ-CARANDE, E., Justicia y seguridad jurídica en un mundo de leyes desbocadas, Civitas, Madrid, 1999, p. 48.

${ }^{28}$ Las opiniones expresadas al respecto, inspiradas a menudo en conceptos de filosofía del Derecho, oscilan entre la concepción de Internet como espacio sin ley (Cyberia, como han dado algunos en llamarlo), por analogía con otros espacios ausentes de soberanía estatal (GIGANTE, A., "Blackhole in cyberspace: the legal void in the Internet”, The John Marshall journal of computer \& information Law, n. 3, 1997, pp. 413 a 436), y la visión de Internet como fenómeno con un nuevo ordenamiento jurídico, a veces llamado lex informatica o lex electronica, propio de una sociedad virtual (BURNSTEIN, M. R.,
}

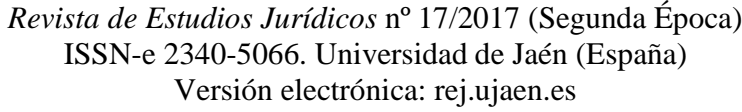


consiguiente desaparición de las fronteras geográficas de cada una de las actividades que acaecen a su albergue ${ }^{29}$. Mientras que la revolución industrial podía ser regulada con relativa autonomía por parte de los distintos ordenamientos estatales (que, en esta época, se dotan de legislaciones internas mediante el fenómeno de la codificación), la repuesta jurídica a la informatización no puede ser circunscrita a nivel estatal, siendo necesaria la adopción de soluciones globales coordinadas y armonizadas que se adecuen de manera satisfactoria a la dimensión transnacional de las distintas actividades que las propician $^{30}$.

Todo ello determina, en definitiva, que la complejidad del fenómeno digital no pueda ser regulada en exclusiva por los Estados individualmente considerados, habiendo de acudir a mecanismos de coordinación y organización de carácter supranacional capaces de imprimir una respuesta suficientemente satisfactoria, equilibrada y uniforme a los problemas derivados del proceso expansivo que, de manera progresiva, se consolida ${ }^{31}$. Y todo ello con una, más que patente, dificultad añadida, cual es la naturaleza territorialmente delimitada de cada Derecho interno y soberano, difícilmente compatible con el carácter global propio de Internet ${ }^{32}$. En estos casos, la organización de intereses comunes en materias concretas se traduce en la determinación de normas a nivel supranacional que necesitan, no obstante, de normas de ejecución a nivel interno, es decir, de actos estatales de transformación de la norma internacional en norma interna (según la teoría dualista) o de adecuación del Derecho interno al Derecho internacional (según la teoría monista). De este modo, el monopolio normativo estatal viene erosionado $^{33}$, al menos en cuanto a la concreción del contenido de la norma, ya que el Estado se limita a dar, con el acto de ejecución, un imprimatur interno, obligatorio desde el momento en que aceptan voluntariamente participar de la organización en cuestión $^{34}$. Tal es el caso, a los efectos que aquí interesan, de las normas que forman parte del Derecho de la Unión Europea, que merman el domino estatal (exclusivo hasta

"Conflicts on the net: choice of Law in transactional cyberspace”, Vanderbilt journal of transactional Law, n. 29, 1996, pp. 75 a 90; DELACOURT, J. T., “The international impact of Internet regulation”, Harvard international law journal, n. 38, 1997, pp. 207 a 235; GAUTRAIS, V./LEFEBVRE, G./ BENYEKHLEF, K., "Droit du commerce électronique et normes applicables: l'emergence de la lex electronica”, Revue de Droit des affaires internationales, n. 5, 1997, pp. 547 a 583; GoulD, M., "Rules in the virtual society”, International review of Law, computers \& technology, n. 2, 1996, pp. 199 a 218; REIDENBERG, J. R., "Lex informatica: the formulation of information policy rules through technology", Texas Law review, n. 3, 1998, pp. 553 a 593).

${ }^{29}$ Sentencia número 96/511 del Tribunal Supremo norteamericano, de 26 de junio de 1997, que declara la inconstitucionalidad de la Ley de decencia de las telecomunicaciones, del Congreso de los Estados Unidos. Para un estudio más profundo de esta sentencia, Vid. FERNÁnDEZ EsTEBAN, M. L., "Limitaciones constitucionales e inconstitucionales a la libertad de expresión en Internet”, Revista española de Derecho constitucional, n. 53, 1998, pp. 283 a 311.

${ }^{30}$ SARTOR, G., L'informatica giuridica e le tecnologie dell'informazione: corso d'informatica giuridica, cit., p. 15.

${ }^{31}$ BARNES VÁZquEZ, J., "La Internet y el Derecho: una nota acerca de la libertad de expresión e información en el espacio cibernético”, Cuadernos de Derecho judicial, n. 6, 1997, pp. 235 a 241.

${ }^{32}$ Finocchiaro, G. D./DElfini, F., Diritto dell'informatica, cit., pp. 3 a 42.

${ }^{33}$ MAESTRI, E., Lex informatica: Diritto, persona e potere nell'età del cyberspazio, Edizioni Scientifique Italiane, Nápoles, 2015, p. 95.

${ }^{34}$ FinOCChiaro, G. D./DELFini, F., Diritto dell'informatica, cit., pp. 10 y 11. 
la ratificación del Tratado de Roma y los sucesivos actos modificativos) sobre las reglas jurídicas aplicables a los particulares, hasta el punto de no necesitar, en muchos casos, de medidas internas de ejecución. Estas normas serán tomadas posteriormente como modelo de referencia por otras organizaciones regionales, ubicadas, fundamentalmente, en América del Sur y, en menor medida, en la zona del sudeste asiático ${ }^{35}$. A ello se une la incertidumbre a la hora de determinar, de una parte, los órganos competentes para resolver las cuestiones que se originan en este nuevo espacio y para garantizar la eficacia extraterritorial de las decisiones judiciales que se dicten al respecto y, de otra, la ley aplicable a los procesos que se originan en la $\operatorname{Red}^{36}$.

\section{Servicios de la sociedad de la información en el ordenamiento jurídico español: marco normativo regulador}

El verdadero reto de toda Ley que pretenda regular cualesquier aspecto de la sociedad de la información será conseguir que ciudadanos y empresas incorporen la Red a su vida cotidiana. Para ello, el objetivo primordial de la norma tendrá que ser imprimir seguridad y confianza pero sin mermar, al mismo tiempo, la libertad de mercado ${ }^{37}$. Para la consecución de estos fines se crea, a nivel europeo, la $\mathrm{DCE}^{38}$, que persigue contribuir al correcto funcionamiento del mercado interior garantizando la libre circulación de los servicios de la sociedad de la información (en adelante, SSI) entre los Estados miembros y aproximando determinadas disposiciones nacionales que resulten de aplicación, relativas a cuestiones tales como el mercado interior, el establecimiento y responsabilidad de los prestadores de servicios de la sociedad de la información (en adelante, PSSI), las comunicaciones comerciales, los contratos por vía electrónica, los códigos de conducta, los acuerdos extrajudiciales para la solución de litigios, los recursos judiciales y la cooperación entre Estados miembros ${ }^{39}$.

\footnotetext{
${ }^{35}$ Sobre los aspectos concernientes al ámbito de extensión de los modelos comunitarios más allá de los confines geográficos europeos, Vid. PANEBIANCO, M., Introduzione al Diritto comunitario comparato: Diritto internazionale e Diritto dell'integrazione nell'Europa comunitaria e in America Latina, Edisud, Aix-en-Provence, 1985.

${ }^{36}$ Sobre esta cuestión, resulta especialmente útil la obra, antes citada, de CALvo CARAVACA, A./ CARrascosa GonzÁlez, J., Conflictos de leyes y conflictos de jurisdicción en Internet, Colex, Madrid, 2001., pp. 13 a 167.

${ }^{37}$ Cremades GarcíA, J./GOnZÁLEz Montes, J. L., La nueva Ley de Internet: comentarios a la Ley 34/2002, de 11 de julio, de Servicios de la Sociedad de la Información y de Comercio Electrónico, La Ley-Actualidad, Las Rozas, 2003, p. 80.

38 Directiva 2000/31/CE del Parlamento Europeo y del Consejo de 8 de junio de 2000 relativa a determinados aspectos jurídicos de los servicios de la sociedad de la información, en particular el comercio electrónico en el mercado interior (Directiva sobre el comercio electrónico) -DOCE L 178, de 17 de julio de 2000, p. 1-.

${ }^{39}$ Es, esta, una Directiva de armonización (DíAz FrAILE, J. M., "El comercio electrónico: Directiva y Proyecto de Ley español de 2000. Crónica de su contenido, origen, propósitos y proceso de elaboración”, cit., pp. 31 y 32).
} 
En España, es la $\operatorname{LSSICE}^{40}$ la encargada de incorporar al ordenamiento jurídico interno la DCE ${ }^{41}$. Esta Ley tiene como objeto (artículo 1) la regulación del régimen jurídico de los SSI en lo atinente a las obligaciones y consiguiente régimen sancionador de los PSSI, las comunicaciones comerciales virtuales, la información (previa y posterior) que han de proporcionar, la validez y la eficacia de los contratos de naturaleza electrónica. Las disposiciones contenidas en esta norma, prosigue el precepto, «se entenderán sin perjuicio de lo dispuesto en otras normas estatales o autonómicas ajenas al ámbito normativo coordinado ${ }^{42}$, o que tengan como finalidad la protección de la salud y seguridad pública, incluida la salvaguarda de la defensa nacional, los intereses del consumidor, el régimen tributario aplicable a los servicios de la sociedad de la información, la protección de datos personales y la normativa reguladora de defensa de la competencia» ${ }^{43}$. De este modo, partiendo de la aplicación a las actividades realizadas por medios electrónicos de las normas tanto generales como especiales que las regulan, la LSSICE se ocupará tan sólo de aquellos aspectos que, ya sea por su novedad o por las peculiaridades que implica su ejercicio online, no se hallan cubiertos por dicha regulación.

\footnotetext{
${ }^{40}$ Ley 34/2002, de 11 de julio, de servicios de la sociedad de la información y de comercio electrónico (BOE núm. 166, de 12 de julio de 2002).

${ }^{41}$ También, de modo parcial, la Directiva 98/27/CE del Parlamento Europeo y del Consejo de 19 de mayo de 1998 relativa a las acciones de cesación en materia de protección de los intereses de los consumidores (DOCE L 166, de 11 de junio de 1998, p. 51).

${ }^{42}$ El ámbito normativo coordinado, en términos expresados por la DCE -artículo 2.h) y considerando (21)-, hace referencia a los requisitos exigibles a los PSSI en los regímenes jurídicos de los Estados miembros, independientemente de si estos requisitos son de tipo general o destinados específicamente a los mismos. Más concretamente, alude a las exigencias que el PSSI debe cumplir en relación con dos aspectos: de un lado, el inicio de la actividad de un SSI, donde se encuentran aquellas condiciones relacionadas con cualificaciones, autorizaciones o notificaciones; de otro, el ejercicio de la actividad de un SSI, como las exigencias relacionadas con el comportamiento del PSSI, con la calidad o el contenido del SSI (incluidos los aplicables a publicidad y contratos) o con la responsabilidad del PSSI. En cambio, el ámbito normativo coordinado no se refiere a aquellos requisitos aplicables a las mercancías en sí, a la entrega de las mismas o a los servicios no prestados por medios electrónicos. Este término es trasladado a nuestro ordenamiento jurídico interno, en términos prácticamente idénticos, en el anexo, apartado i), LSSICE, que delimita el ámbito normativo coordinado como el conjunto de requisitos exigidos aplicables a los PSSI, ya vengan exigidos por la presente Ley u otras normas que regulen el ejercicio de actividades económicas por vía electrónica, ya vengan impuestos por las leyes generales que les sean de aplicación; en todo caso, continúa, deberá referirse a los siguientes aspectos: en primer lugar, al comienzo de la actividad, como las titulaciones profesionales o cualificaciones requeridas, la publicidad registral, las autorizaciones administrativas o colegiales precisas o los regímenes de notificación a cualquier órgano u organismo público o privado, y, en segundo lugar, al ejercicio posterior de dicha actividad, como los requisitos referentes a la actuación del PSSI; a la calidad, seguridad y contenido del SSI; a la publicidad y a la contratación electrónicas, o a la responsabilidad del PSSI. La LSSICE concluye advirtiendo que no quedan incluidas en este ámbito las condiciones relativas a las mercancías y bienes tangibles, a su entrega ni a los servicios no prestados por medios electrónicos.

${ }^{43}$ La LSSICE se completa con otras normas relativas a cuestiones varias, como contratación a distancia, protección de los consumidores, propiedad intelectual, pago electrónico, servicios financieros, protección de la intimidad y frente al tratamiento de datos o, a los efectos que aquí interesan, firma y sello electrónicos. Sobre esta cuestión, Vid. PlazA PenAdÉs, J., Derecho y Nuevas Tecnologías de la Información y la Comunicación, Aranzadi, Cizur Menor, 2013, p. 60.
} 


\section{Concepto y caracteres: servicios de la sociedad de la información como concepto general aglutinador de figuras heterogéneas}

A nivel comunitario, fue manifiesto el interés que, desde un principio, suscitó el fenómeno de la sociedad de la información, tratando de evitar que las normas que los diversos Estados miembros dictaran en relación con los servicios prestados a su amparo pudieran suscitar divergencias susceptibles de perjudicar la realización del objetivo de integración económica y de libre prestación de servicios en el seno de la UE ${ }^{44}$. Como parece obvio, cualquier intervención legislativa en relación con estos nuevos servicios requería de una previa definición legal que permitiera, de un lado, delinear sus contornos esenciales, y, de otro, posibilitar su diferenciación respecto de otras prestaciones de distinta naturaleza. Se acuña, así, el término servicios de la sociedad de la información.

Al contrario de lo que pudiera pensarse, el texto normativo encargado de proporcionar una definición de SSI no es aquel que regula su objeto. En efecto, la DCE, en su artículo 2.a), efectúa una remisión al apartado segundo del artículo 1 de la Directiva 98/34/CE del Parlamento Europeo y del Consejo de 22 de junio de 1998 por la que se establece un procedimiento de información en materia de las normas y reglamentaciones técnicas ${ }^{45}$, modificada, a su vez, por la Directiva 98/48/CE del Parlamento Europeo y del Consejo de 20 de julio de $1998^{46}$. De acuerdo con este precepto, será SSI «todo servicio prestado normalmente a cambio de una remuneración, a distancia, por vía electrónica y a petición individual de un destinatario de servicios». Se entenderá que es a distancia aquel servicio que sea prestado sin que las partes se hallen presentes de manera simultánea, es decir, sin la presencia física sincrónica de la persona que presta el SSI (PSSI) y su destinatario (destinatario de servicios de la sociedad de la información, en adelante DSSI); por vía electrónica, cuando sea enviado desde la fuente y recibido por el DSSI mediante equipos electrónicos de tratamiento (incluida la compresión digital) y de almacenamiento de datos y que se transmite, canaliza y recibe íntegramente por hilos, radio, medios ópticos o cualquier otro medio electromagnético ${ }^{47}$, y a petición individual de un destinatario de servicios, cuando sea este quien solicite que el servicio le sea prestado ${ }^{48}$. Por último, el SSI tendrá carácter oneroso cuando ambas partes intervinientes obtengan algo de manera recíproca, es decir, cuando tanto el PSSI como el DSSI realicen una prestación a favor de la otra

\footnotetext{
${ }^{44}$ Peguera Poch, M., Principios de Derecho de la sociedad de la información, Aranzadi, Cizur Menor, 2010, p. 319.

${ }^{45}$ DOCE L 204, de 21 de julio de 1998, p. 37.

${ }^{46}$ DOCE L 217, de 5 de agosto de 1998, p. 18.

47 Como señala PlazA PenAdÉs, J., Derecho y Nuevas Tecnologías de la Información y la Comunicación, cit., p. 46, lo que se quiere poner de manifiesto es que el SSI de que se trate debe prestarse a través de una red de comunicación, con independencia de cómo se produzca el acceso a la Red, ya sea por teléfono móvil, por televisión o por ordenador.

${ }^{48}$ On demand, de modo que los SSI están puestos a disposición de cualquier persona que lo desee, que podrá acceder a ellos de manera individualizada y en cualquier momento (Ibid., p. 46).
}

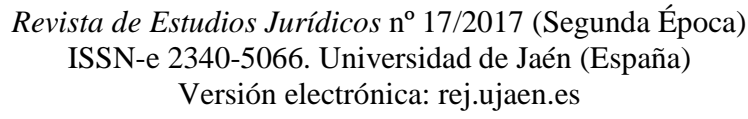


parte $^{49}$. Pese a esta última afirmación, conviene tener presente el contenido del considerando (18) DCE, que aclara que los SSI no cubren únicamente aquellos servicios que dan lugar a la contratación en línea, sino que, en la medida en que representen una actividad económica, serán extensivos igualmente a servicios que no son remunerados por sus destinatarios. En opinión de DÍAZ FRAILE ${ }^{50}$, es esta naturaleza onerosa de la prestación una nota esencial, ya que lo que se incluye es toda actividad desarrollada por vía electrónica y que tenga un significado económico, más allá de que sea el usuario final, o no, el que deba pagar el servicio de que se trate. De este modo, se habrán de entender incluidos dentro de la noción de PSSI a todos aquellos que obtengan ingresos económicos como consecuencia del servicio, ya sea directamente (como es el caso de los servicios remunerados por sus destinatarios) o indirectamente (a través de la inclusión de publicidad o como consecuencia de la explotación de datos personales de los usuarios que se registran para acceder al servicio) ${ }^{51}$. Quedarían fuera, por contra, todos los demás supuestos en los que quepa apreciar una ausencia total de actividad económica, como suele ocurrir con las páginas o blogs de carácter personal, que deberán ser excluidos del régimen jurídico específico de los PSSI.

En concreto, del considerando (18) DCE se desprenden algunos SSI (enumeración, esta, no exhaustiva o numerus apertus) que se considerarán incluidos en el ámbito de aplicación de la norma. Entre ellos, cabría citar toda una amplia variedad de actividades económicas que se desarrollan en línea, en particular aquellas que consisten en la venta de mercancías por medios electrónicos. Ahora bien, como anticipábamos en líneas anteriores, dentro de esta noción se incluyen también, en la medida en que representan una actividad económica, servicios no remunerados por sus destinatarios, como los que consisten en ofrecer información en línea o comunicaciones comerciales; los servicios de la sociedad de la información de intermediación (en adelante, SSIi) que ofrecen instrumentos de búsqueda, acceso y recopilación de datos; los que cubren servicios consistentes en transmitir información a través de una red de comunicación, o los que permiten albergar información facilitada por el destinatario del servicio. Junto a los anteriores, también estarán comprendidos aquellos servicios que se transmitan entre dos

\footnotetext{
${ }^{49}$ ARIAS POU, M., Manual práctico de comercio electrónico, La Ley, Las Rozas, 2006, p. 60.

${ }^{50}$ DíAz FrAiLE, J. M., “El documento electrónico y la firma digital: su regulación en la Unión Europea”, Noticias de la Unión Europea, n. 177, 1999, pp. 17 y 18. En la misma línea, PlAZA PENADÉS, J., Propiedad intelectual y sociedad de la información: Tratados OMPI, Directiva 2001/29/CE y responsabilidad civil en la Red, Aranzadi, Cizur Menor, 2002, p. 229.

51 AdSUARA VARELA, B., “Algunas consideraciones previas sobre el comercio electrónico”, Información comercial española, n. 813, 2004, p. 16; DE Miguel AsEnSiO, P. A., Derecho privado de Internet, Civitas, Madrid, 2001, p. 134; LÓPEZ RICHART, J., "Difamación en la web 2.0 y responsabilidad civil de los prestadores de servicios de alojamiento”, Derecho privado y Constitución, n. 26, 2012, p. 160. Consciente de la dificultad que, en ocasiones, puede entrañar la determinación del carácter económico de un determinado servicio, Peguera Poch, M., Principios de Derecho de la sociedad de la información, cit., pp. 320 y 321, compara seguidamente dos ejemplos claramente ejemplificativos al respecto y que constituyen extremos opuestos: un primer ejemplo, como sería el caso del buscador Google, donde el criterio de la obtención de ingresos indirectos por vía de publicidad es útil para apreciar la naturaleza económica de la prestación, y un segundo ejemplo, concretado en toda página web personal que se limita a incluir un simple banner publicitario, donde este mismo criterio no determina, per se, el carácter oneroso del servicio.
} 
puntos, como el vídeo a la carta o el envío por correo electrónico ${ }^{52}$ de comunicaciones comerciales.

En cambio, prosigue el considerando anterior, no tendrán la consideración de SSI actividades como la entrega de mercancías en sí misma o la prestación de servicios fuera de línea, ni, tampoco, los servicios de radiodifusión televisiva ${ }^{53}$ o radiofónica, ya que ninguno de ellos se presta a petición individual del destinatario de la prestación. El uso del correo electrónico o, por ejemplo, de sistemas equivalentes de comunicación entre individuos, por parte de personas físicas que actúan fuera de su profesión, negocio o actividad profesional, incluso cuando los usen para celebrar contratos entre sí, no constituirán, en ningún caso, un $\mathrm{SSI}^{54}$; lo mismo sucederá con la relación contractual

\footnotetext{
${ }^{52}$ No encontramos en nuestro Derecho un concepto legal de correo electrónico. No obstante, el artículo 2.h) de la Directiva 2002/58/CE del Parlamento Europeo y del Consejo de 12 de julio de 2002 relativa al tratamiento de los datos personales y a la protección de la intimidad en el sector de las comunicaciones electrónicas (Directiva sobre la privacidad y las comunicaciones electrónicas) -DOCE L 201, de 31 de julio de 2002, p. 37-, sí proporciona una definición al respecto. De acuerdo con la misma, se entenderá por correo electrónico «todo mensaje de texto, voz, sonido o imagen enviado a través de una red de comunicaciones pública que pueda almacenarse en la Red o en el equipo terminal del receptor hasta que éste acceda al mismo».

${ }^{53}$ Definidos en el artículo 1.e) de la Directiva 89/552/CEE del Consejo de 3 de octubre de 1989 sobre la coordinación de determinadas disposiciones legales, reglamentarias y administrativas de los Estados miembros relativas al ejercicio de actividades de radiodifusión televisiva (DOCE L 298, de 17 de octubre de 1989, p. 23), modificada, primero, por la Directiva 97/36/CE del Parlamento Europeo y del Consejo de 30 de junio de 1997 (DOCE L 202, de 30 de julio de 1997, p. 60), y, después, por la Directiva 2007/65/CE del Parlamento Europeo y del Consejo de 11 de diciembre de 2007 (DOUE L 332, de 18 de diciembre de 2007, p. 27).

${ }^{54}$ Para entender este supuesto incluido en el ámbito de aplicación de la norma se requiere, por tanto, que el uso del correo electrónico (o de sistemas equivalentes de comunicación entre individuos) para realizar comunicaciones comerciales o, incluso, para celebrar contratos electrónicos entre sí, se realice por personas jurídicas o por personas físicas, siempre que, al menos una de ellas (el PSSI), actúe dentro de su actividad profesional. Resultado de lo anterior, cuatro situaciones se antojan posibles: en primer lugar, que el uso del correo electrónico (o de sistemas equivalentes de comunicación) se produzca entre personas jurídicas, es decir, que tanto el PSSI (que siempre ha de actuar en el marco de su profesión, negocio o actividad profesional) como el DSSI (que puede, o no, actuar en el marco de su profesión, negocio o actividad profesional) sean personas jurídicas; en segundo lugar, que el uso del correo electrónico (o de sistemas equivalentes de comunicación) se lleve a cabo entre una persona física y una persona jurídica, es decir, que el PSSI sea una persona física y el DSSI una persona jurídica o viceversa; en tercer lugar, que el uso del correo electrónico (o de sistemas equivalentes de comunicación) se realice por personas físicas, es decir, que tanto el PSSI como el DSSI sean personas físicas, y, en cuarto y último lugar, que el uso del correo electrónico (o de sistemas equivalentes de comunicación) se realice por personas físicas y que ninguna de ellas actúe en el marco de su profesión, negocio o actividad profesional, es decir, que ninguno de ellos tenga la consideración de PSSI (no teniendo el otro, por ende, la consideración de DSSI). Los tres primeros constituirán un SSI, no siendo así en el último de ellos. Para algunos autores (Ibid., pp. 325 y 326), la mera comunicación efectuada por vía electrónica entre dos personas que actúan en un ámbito ajeno al de su profesión, negocio o actividad profesional, no significa que se estén prestando mutuamente SSI; es esta, entiende, la razón por la cual la DCE excluye expresamente este supuesto de la noción de SSI, dado que no tendría sentido exigir en tal supuesto el cumplimiento de los requisitos que se imponen al PSSI. Yo tengo mis dudas al respecto, habida cuenta de que, desde un punto de vista estrictamente formal, el cumplimiento de los requisitos que forman parte del concepto de SSI sería causa justificativa suficiente para encuadrar también este supuesto dentro del ámbito de aplicación de la DCE, contribuyendo, así, a reforzar la certeza y seguridad jurídica de cuantos
} 
entre un empleado y su empresario o con aquellas actividades que, por su propia naturaleza, no puedan realizarse a distancia ni por medios electrónicos, entre las que se incluirían el control legal de la contabilidad de las empresas o el asesoramiento médico que implica el reconocimiento físico de un paciente.

Además, a la definición contenida en la Directiva 98/34/CE se acompaña una lista indicativa, contenida en su anexo $\mathrm{V}$, en la que figuran expresamente servicios no cubiertos por este concepto. De acuerdo con la misma, no serán SSI aquellos que no sean ofrecidos a distancia, o, lo que es lo mismo, aquellos que se presten en presencia física del PSSI y del DSSI, aun cuando impliquen la utilización de dispositivos electrónicos (entre ellos se encuentran, entre otros, la revisión médica o tratamiento en la consulta de un médico con la utilización de equipo electrónico pero con la presencia física del paciente, la consulta en la tienda de un catálogo electrónico en presencia física del cliente, la reserva de billetes de avión a través de una red de ordenadores realizada en una agencia de viajes en presencia física del cliente o los juegos electrónicos en un salón recreativo en presencia física del usuario). Tampoco gozarán de esta consideración los servicios que no sean ofrecidos por vía electrónica, como son los que tienen un contenido material, aunque se presten utilizando dispositivos electrónicos ${ }^{55}$ (habría que incluir aquí la expendeduría automática de billetes de banco o ferrocarril o el acceso a redes de carretera o aparcamiento de pago, aun cuando en las entradas o salidas haya dispositivos electrónicos que controlen el acceso o aseguren el pago adecuado); los que se prestan off line o fuera de línea (como la distribución de CDROM o de programas informáticos en disquetes), o los que no son prestados por medio de sistemas electrónicos de tratamiento o almacenamiento de datos (servicios de telefonía vocal, servicios de fax y télex, servicios prestados por medio de telefonía vocal o fax o consultas médica o jurídica o marketing directo por teléfono o fax). Por último, carecerán también de esta consideración los servicios que no sean prestados a petición individual del destinatario mediante una comunicación individual (transmisión punto a punto), estando destinados, por tanto, a la recepción simultánea por un número ilimitado de destinatarios (transmisión punto a multipunto) ${ }^{56}$; se incluirían en este supuesto los servicios de broadcasting o radiodifusión, tanto televisiva (incluidos los servicios de cuasivídeo a la carta ${ }^{57}$ ) como sonora, y el teletexto (televisivo).

realizan una prestación por vía electrónica, máxime cuando tengan la condición de consumidores, ávidos de una especial protección jurídica que, de este modo, se vería ciertamente mermada.

${ }^{55}$ No hay que confundir este supuesto con el conocido como comercio electrónico indirecto, en el que, como tendremos ocasión de analizar más detalladamente, la ejecución de la obligación se efectúa por medios tradicionales, si bien el resto de fases se llevan a cabo de manera electrónica.

${ }^{56}$ Como acertadamente señalaran NESPOR, S./CESARIS, A. L., Internet e la legge: la persona, la proprietà intellettuale, il commercio elettronico, gli aspetti penalistici, Hoepli, Milán, 2001, p. 49, es esta una diferencia básica entre los servicios de telecomunicación y los servicios de radiotelevisión y radiodifusión, pues los primeros transmiten mensajes entre dos sujetos determinados, mientras que los segundos hacen lo propio entre un sujeto emitente y una pluralidad de sujetos receptores.

${ }^{57}$ Como vimos en el apartado anterior, el vídeo a la carta sí sería un SSI, a la vista de lo dispuesto por el considerando (18) DCE. 
En nuestro ordenamiento jurídico interno, y en términos prácticamente idénticos, la LSSICE ha optado también por incluir, en el apartado a) de su anexo, una definición de SSI $^{58}$. A ellos habrían de añadirse, aquellos SSIi relativos a la provisión de acceso a la Red (Internet service providers), los que permiten la transmisión de datos por redes de telecomunicaciones (mere conduit o routing), los concernientes a la realización de copia temporal de las páginas de Internet solicitadas por los usuarios (proxy caching o memoria tampón), los que posibilitan el alojamiento, en los propios servidores, de información, servicios o aplicaciones facilitados por otros (hosting), los que proveen instrumentos de búsqueda o de enlaces a otros sitios de Internet (searching and linking) o cualquier otro servicio que se preste a petición individual de los usuarios (como la descarga de archivos o audio), siempre que representen una actividad económica para el prestador de servicios de la sociedad de la información (en adelante, PSSIi) ${ }^{59}$.

\section{LA NOCIÓN DE DOCUMENTO EN EL ÁMBITO DE LA CONTRATACIÓN ELECTRÓNICA}

\section{Elementos esenciales y clasificación del documento en su concepción actual}

Estos elementos esenciales se han concretado tradicionalmente en torno a los siguientes ${ }^{60}$ : en primer lugar, el soporte físico o continente, en su concepción de documento como cosa muebles que puede ser llevada ante el juez a los efectos que resulten procedentes, requisito que, como hemos visto, se está viendo modificado legislativamente de manera acorde a los cambios informáticos; en segundo lugar, el contenido o acto documentado, que será el hecho relevante representado en el documento y que permanece intacto tras la introducción de los avances tecnológicos; en tercer lugar, el/los autor/es del documento, que serán las personas a las que se atribuya su formación o la asunción de su contenido, que también se conserva en toda su integridad, y, en cuarto y último lugar, la forma, donde se habrán de incorporar nociones más amplias de documento que permitan incluir, además de representaciones de hechos mediante escritura, las practicadas por otros medios como la imagen o el sonido.

De ello podemos extraer dos conclusiones importantes: en primer lugar, como podemos observar, el documento no requiere de firma ni de fecha para que sea válido y eficaz, si bien a nadie escapa (y así se hará constar) que ambos elementos constituyen

\footnotetext{
${ }^{58}$ El punto 18 de la disposición derogatoria LGCA (BOE núm. 79, de 1 de abril de 2010) eliminó el punto 6 de la letra a) del anexo LSSICE, que incluía entre los SSI, siempre que representase una actividad económica, «el vídeo bajo demanda, como servicio en que el usuario puede seleccionar a través de la Red, tanto el programa deseado como el momento de su suministro y recepción, y, en general, la distribución de contenidos previa petición individual».

${ }^{59}$ GONZÁLEZ GRANDA, P., "Protección judicial de consumidores y usuarios en el ámbito del comercio electrónico”, Indret: revista para el análisis del Derecho, n. 4, 2007, p. 7.

${ }^{60}$ STS núm. 865/1997, de 13 de junio.
} 
un instrumento ciertamente relevante para la satisfacción del fin probatorio que todo documento, sea de la naturaleza que sea, trata de satisfacer; en segundo lugar, a la vista de lo anterior, la asunción legal del concepto en los términos expuestos no obstaculizaría de ninguna manera el cumplimiento de las funciones propias de todo documento, que se resumen en las siguientes: función perpetuadora, en cuanto fijación material de unas manifestaciones del pensamiento; función probatoria, en cuanto acreditación o prueba de un hecho concreto, donde el documento podrá verse acompañado de instrumentos adicionales que, por sus características, persigan el mismo fin (caso de la firma), y, en tercer y último lugar, una función garantizadora, en cuanto sirve para asegurar que la persona identificada en el documento es la misma que ha realizado las manifestaciones que se le atribuyen en el mismo ${ }^{61}$.

A su vez, podemos establecer distintas clasificaciones actualmente válidas de documento, atendiendo a criterios varios que podrán, o no, darse cumulativamente en un mismo supuesto ${ }^{62}$ :

En primer lugar, por el origen, podemos distinguir entre documento público y documento privado. El documento público es aquel que realizado por un funcionario público en el desempeño de sus funciones; dentro de él, podremos hablar, a su vez, de documento oficial y documento público propiamente dicho: ambos provienen de sujetos que desempeñan una función pública, pero, en este último, la persona tiene encomendada específicamente la función de dar fe pública sobre el contenido del documento. El documento privado, en cambio, será el realizado por un particular o persona privada.

En segundo lugar, por el continente en que se encuentra recogido el documento, y fruto de la irrupción del elemento virtual en el análisis de la realidad actual ahora diseccionada, hablaremos de soporte papel y de soporte electrónico.

En tercer lugar, por el contenido propio del documento, a los efectos que aquí nos interesan, cabría diferenciar entre documentos portadores de contratos y documentos no portadores de contratos. Un documento contractual sería aquel que contiene la oferta por el vendedor, la aceptación del destinatario, las condiciones generales de la contratación que afectan a la relación negocial o, conjuntamente, el contenido y el consentimiento de las partes en obligarse recíprocamente.

En cuarto lugar, según el documento esté, o no, refrendado por su autor o por la persona que acepta su contenido, estaremos ante un documento firmado o ante un documento no firmado. Asimismo, el documento firmado, según se trate de documento recogido en soporte papel o en soporte electrónico, estará refrendado por una firma manuscrita o por una firma electrónica, que, además, podrá presentar distintos niveles de seguridad, según se trate de firma electrónica simple, avanzada o reconocida o

\footnotetext{
${ }^{61}$ Ibid., F. J. $3^{\circ}$.

${ }^{62}$ Menéndez Mato, J. C./Gayo Santa Cecilia, M. E., Derecho e informática: ética y legislación, Bosch, Vallirana, 2014, pp. 243 a 245.
} 
cualificada. Como decíamos antes, este requisito no afecta a la validez o eficacia del documento, que podrá existir aun sin venir acompañado de firma, en cuyo caso podremos llegar a determinar la autoría o la presunción del contenido del documento acudiendo a otros medios de prueba de los contemplados en el artículo 299 LECiv $^{63}$. En todo caso, es obvio que, a los efectos de imputar su contenido a una persona determinada, la firma juega un papel esencial: si estamos ante un documento físico en soporte papel, la firma manuscrita servirá para presumir dicha autoría o aceptación de su contenido por quien aparece como firmante o signatario, si bien se tratará de una presunción iuris tantum que podrá ser rebatida acudiendo, por ejemplo, a una prueba caligráfica; si estamos ante un documento electrónico en soporte digital, la firma electrónica (dependiendo del nivel de seguridad que ofrezca) podrá determinar igualmente la paternidad y la integridad del documento del mismo modo que la firma manuscrita, no sirviendo, en cambio, para rebatirla, al menos íntegramente, los mismos medios que para la firma tradicional.

Por último, en atención a su valor probatorio, estaremos ante documentos que constituyen prueba plena en juicio, que serán los del artículo 299.1 LECiv, y documentos que serán valorados conforme a las reglas de la sana crítica, contenidos en los apartados 2 y 3 de dicho precepto.

\section{Teoría dualista tradicional en torno al documento: mismos problemas, distinto enfoque}

Un siguiente paso en nuestro estudio exige analizar la naturaleza jurídica del contrato electrónico como soporte de derechos y obligaciones articulado por medios digitales. Ello supone considerar, como elemento matriz, la figura del documento ${ }^{64}$, que servirá de fundamento primero con el que poder probar, en su caso, la existencia de la relación contractual, la identidad de los sujetos que en ella intervengan y la integridad misma de su contenido ${ }^{65}$.

\footnotetext{
${ }^{63}$ Ley 1/2000, de 7 de enero, de enjuiciamiento civil (BOE núm. 7, de 8 de enero de 2000).

${ }^{64}$ El término documento encuentra su origen entre los griegos: el prefijo dék viene de dékos, que se refiere a un gesto de la mano que se hacía para recibir u ofrecer, fundamentalmente en manifestaciones de carácter religioso. Posteriormente, los latinos retoman la expresión bajo el vocablo docere, que se traduce como aquello que se enseña, instruye o informa. Ambos términos pueden traducirse, en consecuencia, por la expresión mostrar algo a alguien (JOLY-PASSANT, E., L'écrit confronté aux nouvelles technologies, Lgdj, París, 2006, pp. 63 y 68). A su vez, desde un punto de vista evolutivo, Vid. DEvis Echandía, H., Teoría general de la prueba judicial, Zavalía, Buenos Aires, 1970, pp. 496 y ss.

${ }^{65}$ ORTiZ NAVACERRADA, S., La prueba de documentos en el proceso civil: estudio jurisprudencial, Actualidad, Alcobendas, 1994, p. 15, hace referencia al hecho de afrontar, desde el principio, el concepto de documento como algo fundamental y no como una cuestión meramente retórica o académica. En la misma línea, ElíAs BATURONES, J. J., La prueba de documentos electrónicos en los tribunales de justicia, Tirant lo Blanch, Valencia, 2008, p. 1.
} 
El diccionario de la Real Academia de la Lengua define el término documento, en la segunda de sus acepciones, como «[e]scrito en el que constan datos fidedignos o susceptibles de ser empleados como tales para probar algo». El término escrito procede del participio escribir, que viene a significar la representación de palabras o ideas con letras u otros signos trazados en papel u otra superficie, siendo las letras cada uno de los signos gráficos que componen el alfabeto de un idioma (primera acepción) y los signos los objetos, fenómenos o acciones materiales que, por naturaleza o convención, representan o sustituyen a otro (primera acepción). A su vez, por dato se entiende la «[i]nformación sobre algo concreto que permite su conocimiento exacto o sirve para deducir las consecuencias derivadas de un hecho» (primera acepción) o, en términos informáticos, la «[i]nformación dispuesta de manera adecuada para su tratamiento por una computadora» (tercera acepción). Por último, soporte será aquel «[m]aterial en cuya superficie se registra información, como el papel, la cinta de vídeo o el disco compacto» (cuarta acepción) $^{66}$. De todo ello podemos extraer una definición de documento, a los efectos que aquí interesan, como soporte en papel u otro formato adecuado que contiene letras o signos que proporcionan información, escrita, vista o hablada, fidedigna o relevante sobre hechos con eficacia probatoria o cualquier otro tipo de utilidad jurídica ${ }^{67}$.

Esta afirmación, aparentemente sencilla, ha sido objeto de controversia a lo largo de la historia, dando lugar a debates que, como no, han tenido también su reflejo en distintos textos legales que, de alguna u otra manera, proceden a regular los efectos derivados del documento. Consecuencia de lo anterior, podemos destacar la existencia de dos teorías fundamentales en torno a la configuración (doctrinal ${ }^{68} \mathrm{y}$ jurisprudencial $^{69}$ ) del documento desde un punto de vista jurídico:

\footnotetext{
${ }^{66}$ ReAl ACADEMia EsPaÑola, Definiciones de documento, escribir, letra, signo, dato y soporte, 2017.

${ }^{67}$ Elaboración propia.

68 Almagro Nosete, J., Derecho procesal, Tirant lo Blanch, Valencia, 1996, pp. 85 a 91; V. CARRASCOSA LÓPEZ, V., "Valor probatorio del documento electrónico", Informática y Derecho: revista iberoamericana de Derecho informático, n. 8, 1995, pp. 138 y 139, 147 a 164; MONTERO AROCA, J., La prueba en el proceso civil, Civitas, Madrid, 2001, p. 200.

69 De esta dicotomía se hace eco también la jurisprudencia de nuestro país, como muestra la STS núm. 293/1994, de 24 de marzo, F. J. $2^{\circ}$, cuando, en relación con el término documento, diferencia entre «[...] la clásica doctrina que le reputa como sinónimo de escrito a través del cual se exterioriza una idea, pensamiento, convención, negocio jurídico, etc., el cual parece ser se estimó por el legislador procesal de 1881 y no tan exactamente por el civil de 1889, en los artículos 596 y 602 aquél y en los (artículos) 1216 a 1230 éste» y lo que «[...] la doctrina procesalista actual califica de funcional, a virtud del cual el concepto de documento ofrece una mayor amplitud en cuanto referido al medio u objeto a través del cual se manifiesta ese pensamiento, idea, etc. -cintas de película o vídeo, estatuas, discos, etc.-, lo que viene en cierto modo amparado por el artículo 1215 CC (que no se encuentra en vigor tras la disposición derogatoria única. 2.1 LECiv -BOE núm. 7, de 8 de enero de 2000-), al emplear el término "instrumentos" en lugar del de "documentos", y que tiene su proyección jurisprudencial entre otras en la Sentencia de esta Sala de 24 de febrero 1956, en la que se concede el carácter de documento a un modelo de cerradura incorporado a los autos, o en la Sentencia de la Sala Sexta (hoy $4 .^{\text {a) }}$ del TS de 5 de julio 1984, que amparada precisamente en el término "instrumentos” del citado artículo 1215 CC, admite como prueba documental la grabación de imágenes de vídeo; o la Sentencia del TC número 190/1992 de 16 noviembre y la en ella citada número 128/1988, de 27 de junio, que estiman "no puede negarse valor
} 
Una primera es la conocida como teoría estricta, del escrito, restringida o latina, que sostiene que el documento siempre ha de constar en soporte físico escrito y el escrito en papel, identificando, en mi opinión erróneamente, estos términos como sinónimos o equivalentes ${ }^{70}$. En esta línea se ubican distintos autores que, de forma patente pero implícita, inciden en esta concepción restringida al identificar soporte físico y escritura, de un lado, y escritura y documento, de otro: así sucede con ÁLVAREZ SAAVEDRA $^{71}$, para el que documento no es sino un «[e]scrito con que se prueba, confirma o se hace constar alguna cosa»; ELOSUA DE JUAN ${ }^{72}$, que lo concibe como «[i]nstrumento escrito que ilustra sobre algún hecho», añadiendo su gran importancia jurídica como plasmación de declaraciones de voluntad y como medio de prueba de las mismas, o DE LA OLIVA SANTOS ${ }^{73}$, que por documento entiende aquellos «objetos materiales que incorporan la expresión escrita de un pensamiento humano y son susceptibles de incorporarse a unos autos o a un expediente». A la vista de lo anterior, jurídicamente, será documento todo escrito (archivado en soporte físico en formato papel) en el cual consta la narración y circunstancias de uno o más hechos que constituyen, modifican o extinguen relaciones de Derecho entre dos o más personas.

Esta concepción primigenia de documento se fundamenta en el desconocimiento absoluto que, por entonces, existía respecto de los avances tecnológicos que, con posterioridad, se implantarán de manera incuestionable en nuestra sociedad, razón que determina que distintos cuerpos legales de la época incurran siempre en esta identidad equivocada de vocablos. Así sucede, en concreto, con el $\mathrm{CC}^{74}$ y con la LECiv de $1881^{75}$, que emplean siempre la palabra escrito cuando, en cambio, tenían que haber utilizado la expresión soporte físico, ya que no todos los documentos constan por escrito y no sólo los documentos en soporte físico se sirven de la escritura como medio de representación de la palabra o de la idea.

probatorio a las transcripciones de una cinta magnetofónica, cuando han sido incorporadas a los autos, no han sido impugnadas y se dan por reproducidas en el acto del juicio oral”».

${ }^{70}$ Sobre el carácter histórico de esta postura, Vid. DEVIS ECHANDÍA, H., Teoría general de la prueba judicial, cit., pp. 496 y 497.

71 Álvarez SAAVEDRA, F. J., Diccionario de criminalística. Los secretos de las investigaciones de la policía científica, Planeta, Barcelona, 2003, pp. 246 y 247.

72 Elosua de JuAn, M., Diccionario LID. Comunicación y marketing, Lid, Madrid, 2004, p. 137.

${ }^{73}$ De la Oliva Santos, A., Derecho procesal civil, Centro de estudios Ramón Areces, Madrid, 1995, p. 359. Este mismo autor alude, asimismo, a la necesidad del escrito (concebido erróneamente) en el concepto de documento, afirmando que la voluntad de expandir dicho concepto a realidades técnicas modernas, entre otras adversidades, llevaría a forzar la noción de prueba documental. En concreto, sostiene que ello supone forzar no pocos preceptos acerca de la prueba documental, que estaban razonablemente pensados para el concepto de documento como expresión escrita (véase, de nuevo, la confusión existente en el empleo del término) de un pensamiento humano, corporeizada en objeto incorporable a los autos de un proceso.

${ }^{74}$ Real Decreto de 24 de julio de 1889 por el que se publica el Código Civil (BOE núm. 206, de 25 de julio de 1889).

${ }^{75}$ Real Decreto de 3 de febrero de 1881 por el que se aprueba el proyecto de reforma de la LECiv (BOE núm. 36, de 5 de febrero de 1881). 
Una segunda teoría, fruto de la decadencia de la concepción anterior, tiende a negar la exclusividad del (mal entendido) escrito como elemento definitorio del documento, concibiendo este como todo elemento que ofrezca información, más allá del soporte en el que se contenga. Es la conocida como teoría de la representación o germánica, predominante a partir del momento en el que aparecen con fuerza los avances propiciados por el mundo digital, que obligan a reconsiderar la idea de documento y a proyectarlo como un concepto ciertamente más amplio.

El origen de esta teoría se encuentra en la distinción, efectuada por CARNELUTTI ${ }^{76}$, entre fuentes de prueba y medios de prueba. Según la misma, y partiendo del hecho de que el fenómeno probatorio no pertenece en exclusiva al mundo jurídico, podemos diferenciar entre fuente de prueba, que es un concepto metajurídico, extrajurídico o ajurídico que corresponde a una realidad anterior y extraña al proceso, y medio de prueba, que, por el contrario, es un concepto jurídico y absolutamente procesal. Así, la fuente (lo sustancial y material) existirá con independencia de que se siga, o no, el proceso, mientras que el medio (lo adjetivo y formal) nacerá y se formará en el mismo. De este modo, para poder responder a la cuestión acerca de los elementos con los que poder probar un hecho, es preciso efectuar una separación conceptual entre lo que ya existe en la realidad (fuente) y cómo eso que ya existe en la realidad se aporta al proceso (medio). Consecuencia de lo anterior, aun cuando los medios de prueba sean fijos o numerus clausus (en la LECiv de 1881, confesión en juicio, documentos públicos y solemnes, documentos privados y correspondencia, libros de los comerciantes que se lleven con las formalidades prevenidas, dictamen de peritos, reconocimiento judicial y testigos -artículo 578-; en la LECiv actual, interrogatorio de las partes, documentos públicos, documentos privados, dictamen de peritos, reconocimiento judicial e interrogatorio de testigos -artículo 299.1-), las fuentes de prueba no lo son, más bien todo lo contrario (numerus apertus), ya que pueden venir de múltiples canales, entre ellos, los soportes electrónicos, que, a mi juicio, constituyen una auténtica fuente de prueba documental en el panorama procesal español actual ${ }^{77}$.

Buen exponente de esta nueva concepción lo constituye la STS de 3 de noviembre de $1997^{78}$, que, impregnándose de los cambios que se estaban produciendo, advierte que «estamos asistiendo, en cierto modo, en algunas facetas de la vida, incluso jurídica, al ocaso de la civilización del papel, de la firma manuscrita y del monopolio de la escritura sobre la realidad documental. El documento, como objeto corporal que refleja una realidad fáctica con trascendencia jurídica, no puede identificarse, ya, en exclusiva, con el papel, como soporte, ni con la escritura, como unidad de significación. El ordenador

\footnotetext{
${ }^{76}$ CARnelutTI, F., La prova civile: parte generale. Il concetto giuridico della prova, Giuffrè, Milán, 1992, pp. 70 y ss. Sobre el uso de la expresión fuentes de prueba, Vid. BENTHAM, J., Rationale of judicial evidence: specially applied to English practice, Manuscrito, Londres, 1827, pp. 124 y ss. Más recientemente, pero esenciales en el desarrollo de la distinción entre fuentes y medios de prueba, Vid. Montero ArocA, J., La prueba en el proceso civil, cit., pp. 133, 137 y 138 y SENTís MelEndo, S., La prueba: los grandes temas del Derecho probatorio, Ejea, Buenos Aires, 1979, pp. 141 y ss.

${ }^{77}$ En la misma línea, ELÍAS BATURONES, J. J., La prueba de documentos electrónicos en los tribunales de justicia, cit., p. 4.

${ }^{78}$ STS de 3 de noviembre de 1997, F. J. $10^{\circ}$.
} 
y los ficheros que en él se almacenan constituyen, hoy día, una nueva forma de entender la materialidad de los títulos valores y, en especial, de los documentos mercantiles». En esta misma línea se sitúan autores como RAMOS MÉNDEZ ${ }^{79}$, quien afirma que: «[...] [v]ulgarmente se suele identificar el documento con un escrito. Y, desde luego, los escritos son documentos por antonomasia. Sin embargo, el concepto de documento trasciende al de simple escrito. Este constituye la materia del documento: la escritura en sus diversas formas, la tinta el papel, etc. Pero también existen otras materias que pueden servir de soporte físico a un documento y cada vez con mayor amplitud: cintas magnetofónicas, películas, fotografías, esculturas, fichas o discos de ordenador, ficheros electrónicos, etc. Incluso, elementos que suponen mayores dificultades de traslado físico: inscripciones en monumentos, lápidas conmemorativas, etc.» ${ }^{80}$; también GÓMEZ DE LIAÑO GONZÁLEZ ${ }^{81}$ cuando sostiene que «[...] [d]ocumento, es fundamentalmente un escrito que contiene una declaración de voluntad o de conocimiento, o simplemente una expresión de pensamiento. Suele relacionarse con la idea de escritura porque tradicionalmente era de manera casi exclusiva la forma de contratación. Sin embargo, en el momento presente, las fotografías, películas, discos de ordenador, etc., sirven para incorporar habitualmente una serie de datos que tienen trascendencia en el mundo jurídico, habiendo en este punto quedado atrás la legislación procesal, superada por el avance de los tiempos».

En mi opinión, el problema de este nuevo enfoque, además de su excesiva amplitud, es que incurre en el mismo error que la teoría anterior, ya que, de nuevo, identifica documento con escrito y escrito con soporte físico. Sin embargo, no advierte que, entre las nuevas realidades propiciadas por el nacimiento de la sociedad de la información, se encuentra el documento electrónico, que puede constar también por escrito o, incluso, en formato audiovisual y cuyo soporte no es el físico, sino el electrónico. Esta confusión, heredada en el tiempo, constituirá, precisamente, la base doctrinal que llevará, en la redacción de la LECiv actual, a reconocer legalmente los documentos archivados en soporte electrónico como medio de prueba (artículo 299.2) pero, bajo la denominación de instrumentos, sacarlos fuera de la prueba documental (artículo 299.1. $2^{\circ}$ y $\left.3^{\circ}\right)^{82}$. Así lo pone de manifiesto la propia norma cuando, en su Exposición de Motivos (apartado XI, párrafo $13^{\circ}$ ), afirma expresamente que «[...] [n]o habrá de forzarse la noción de prueba documental para incluir en ella lo que se aporte al proceso con fines de fijación de la certeza de los hechos, que no sea subsumible en las nociones de los restantes medios de prueba. Podrán confeccionarse y aportarse dictámenes e informes escritos, con sólo apariencia de documentos, pero de índole pericial o testifical y no es de excluir, sino que la ley lo prevé, la utilización de nuevos instrumentos probatorios, como soportes, hoy no convencionales, de datos, cifras y cuentas, a los

\footnotetext{
${ }^{79}$ RAmos MÉndez, F., Enjuiciamiento civil, Bosch, Barcelona, 1997, p. 356.

80 ¿Cómo pueden servir de soporte físico a un documento elementos tales como cintas magnetofónicas, películas, fotografías, esculturas, fichas, discos de ordenador, ficheros electrónicos, inscripciones en monumentos o lápidas conmemorativas? no se entiende, ya que se produce una mezcla de medios de prueba y soportes diferentes entre sí.

${ }^{81}$ GÓMEZ dE LiAÑo GONZÁLEZ, F., El proceso civil, Forum, Oviedo, 1990, p. 139.

${ }^{82}$ Vega VegA, J. A., Contratos electrónicos y protección de los consumidores, Reus, Madrid, 2005, p. 237.
} 
que, en definitiva, haya de otorgárseles una consideración análoga a la de las pruebas documentales» ${ }^{83}$. De la lectura de esta norma cabe extraer cuatro conclusiones básicas: en primer lugar, a diferencia de otras ramas de nuestro ordenamiento jurídico, no se contiene definición legal alguna, a efectos procesales civiles, del término documento, cuestión que hubiera contribuido, indudablemente, a clarificar la cuestión que aquí se plantea. En segundo lugar, entiendo que no supone forzar la noción de prueba documental el hecho de concebir como documento algo que, por responder a su concepción clásica, también consta por escrito, si bien no está archivado en el soporte físico tradicional, que ahora se amplía (sin reemplazo alguno) al soporte electrónico. En tercer lugar, tampoco fuerza, la noción de prueba documental la inclusión en el término documento de aquellos archivos que no constan por escrito pero que, a través de la imagen o el sonido, pueden ser igualmente utilizados como instrumentos probatorios. En cuarto lugar, el error de concepto anterior ha obligado a situar lo que también debería ser prueba documental (como es el documento recogido en soporte electrónico, ya sea escrito, visto o hablado) en un apartado distinto al que se le otorga una eficacia probatoria también distinta, y menor: nos referimos al artículo 299.2 LECiv, que nos obliga a remitirnos, a su vez, a los artículos 382 a 384, preceptos que establecen una valoración de este medio de prueba conforme a las reglas de la sana crítica, muy distinta de la prueba plena de la que goza la prueba documental al amparo de los artículos 299.1.3 ${ }^{\circ}$ y 326 LECiv $^{84}$.

\section{Nueva propuesta: el principio de equivalencia funcional como instrumento reparador que ha de ser reelaborado y la teoría del documento como palabra}

\footnotetext{
${ }^{83}$ La cursiva es propia.

${ }^{84}$ A favor de esta visión crítica en la configuración del artículo 299 LECiv, Vid. SANCHÍs CRESPO, C./ Chaveli Donet, E. A., La prueba por medios audiovisuales e instrumentos de archivo en la LEC 1/2000: doctrina, jurisprudencia y formularios, Tirant lo Blanch, Valencia, 2002, p. 57, que afirma que «[l]a vigente LEC ha decidido mantener en el siglo XXI un concepto de documento que identifica como tales sólo a algunos de ellos, excluyendo deliberadamente a los documentos que han surgido de la mano de las nuevas tecnologías»; SERRA Domínguez, M., "La prueba documental”, en Instituciones del nuevo proceso civil. Comentarios sistemáticos a la Ley 1/2000, Dijusa, Madrid, 2000, p. 238, que, desde un punto de vista etimológico, hace referencia a la significación del documento como dar a conocer, de modo que, por tal, habrá de entenderse todo objeto que dé a conocer un hecho determinado. En contra de la misma, pero partiendo, de nuevo, de una concepción errónea del término escrito que lo asimila exclusivamente al que consta en formato o soporte físico papel, Vid. AsEnCIO MELlado, J. M., Derecho procesal civil, Tirant lo Blanch, Valencia, 2015, p. 209, para quien: «[e]n efecto, y de una simple lectura de los textos legales que regulan este medio de prueba, especialmente de la Ley de Enjuiciamiento Civil y el Código Civil, se extrae la conclusión de que el documento no es otra cosa que una representación de la realidad plasmada por escrito. Documento susceptible de encuadrarse en el medio de prueba documental sólo sería el reflejado por medio de la escritura. Esta radical conclusión que bajo la vigencia de la anterior LEC suscitó graves inconvenientes dada la aparición en este siglo de medios a través de los cuales se representaba la realidad pero llevados a efectos en soportes de otra naturaleza (grabaciones videográficas, correo electrónico, etc.) se ha superado con nitidez y rotundidad al regularse un específico mecanismo para su incorporación diferenciada. La prueba documental, así, es la plasmada por la clásica escritura; los restantes medios que aparezcan en otro tipo de soportes se incorporarán a través de los mecanismos establecidos en los arts. 382 a 384».
} 
Interesa destacar en este punto el artículo 9.1 DCE y, tanto más, el artículo 23.3 LSSICE, que tratan de solventar el problema, heredado a lo largo del tiempo, de la errónea identificación entre documento y escrito y entre escrito y soporte físico. Y lo hacen acudiendo al conocido como principio de equivalencia funcional, (analizado a continuación), que, pese a cumplir el fin para el que fue concebido (como es el de equiparar, dentro de la noción de documento -en el caso presente, en su modalidad de contrato-, al archivado en soporte físico y al archivado en soporte electrónico), emplean términos, en mi opinión, mejorables. En concreto, con la redacción actual de la norma, especialmente de la LSSICE, se mantiene el error de concepto y de identificación tantas veces criticado a lo largo de estas líneas, que simplemente se parchea para evitar sus perniciosos efectos y para hacer operativa la introducción de las nuevas tecnologías en el ámbito del Derecho por medio de la fórmula, adecuada pero planteada en términos equivocados, de la equivalencia funcional. Así, una redacción de la Ley con fines más ambiciosos podría haber quedado redactada de la siguiente manera: «[s]iempre que la Ley exija que el contrato o cualquier información relacionada con el mismo conste por escrito, este requisito se entenderá ampliado a nuevos formatos que presenten características similares y persigan el mismo fin y se considerará satisfecho si el contrato o la información se contiene tanto en un soporte físico como en un soporte electrónico».

En realidad, lo único que se produce con la aparición de la realidad digital es una ampliación en la variedad de soportes (derivada de la aparición de la electrónica) y, con ello, de formatos, que son capaces de albergar, no sólo datos fidedignos o susceptibles de ser empleados como tales para probar algo (definición actual de documento contenida en la Real Academia Española) en forma escrita, sino también en forma vista o hablada, innovación hasta el momento desconocida (y que, por ende, habrá de propiciar la modificación o ampliación de la definición anterior). Esta razón es la que justifica mi propuesta de dar un paso más, en una nueva teoría que podríamos denominar teoría de la palabra, y que amplia la noción de documento, partiendo de la palabra escrita y extendiéndola a la imagen y al sonido, que, ahora sí, pueden quedar archivados para su posterior utilización como medio de prueba en un proceso judicial. Todo ello en una propuesta de definición que, de nuevo, reproducimos: soporte en papel u otro formato adecuado que contiene letras o signos que proporcionan información, escrita, vista o hablada, fidedigna o relevante sobre hechos con eficacia probatoria o cualquier otro tipo de utilidad jurídica. Lo importante, por tanto, no es el formato en que conste el documento, sino que sea apto para erigirse en medio de prueba en juicio, capaz de acompañarse, a su vez, de otros tantos medios, como la firma electrónica, que aporten seguridad adicional en cuanto a la identificación del/de los autor/es y a la integridad de su contenido.

Esta teoría se ve reforzada por la definición que del término documento se contiene en diversos sectores de nuestro sistema jurídico nacional. Así sucede, en primer lugar, 
con el artículo 49.1 $\mathrm{LPHE}^{85}$, que entiende por documento «[...] toda expresión en lenguaje natural o convencional y cualquier otra expresión gráfica, sonora o en imagen, recogidas en cualquier tipo de soporte material, incluso los soportes informáticos»; como podemos observar, bajo la cobertura de esta Ley se incluiría todo tipo de documento, escrito, visto o hablado, que conste en soporte físico o electrónico, expandiendo la noción de documento de forma paralela con el desarrollo de los nuevos avances tecnológicos. En segundo lugar, el artículo 76.3.in fine RITPAJD ${ }^{86}$, que hace lo propio cuando, aun de manera más restringida (no contempla el documento en formato distinto al escrito), afirma que por documento se entenderá «[...] cualquier soporte escrito, incluidos los informáticos, por los que se pruebe, acredite o se haga constar alguna cosa»; vemos cómo aquí sí se incluye el escrito como cualidad también posible de aquellos documentos que se encuentren archivados en soporte electrónico, haciendo mención, además, a la finalidad probatoria que estos están llamados a cumplir. En tercer y último lugar se encuentra el artículo $26 \mathrm{CP}^{87}$, que, al definir el documento como «[...] todo soporte material que exprese o incorpore datos, hechos o narraciones con eficacia probatoria o cualquier otro tipo de relevancia jurídica», proporciona una definición genérica abierta a todo tipo de soporte (físico, electrónico o cualquiera que pueda surgir en el futuro y satisfaga las exigencias previstas) en que dicho documento se pueda archivar, siempre que tenga relevancia probatoria o cualquier otra utilidad de naturaleza jurídica.

En materia contractual, la LSSICE introduce un elemento de conflicto normativo en su confrontación con la LECiv. En efecto, el artículo 24.1.1 ${ }^{\circ}$ LSSICE dispone que la prueba de la celebración de un contrato por vía electrónica (modalidad, como sabemos, de documento electrónico) y de las obligaciones que tienen en él su origen se sujetará a las reglas generales del ordenamiento jurídico. No obstante, y he aquí el problema, añade un apartado segundo, en el que afirma que «[e]n todo caso, el soporte electrónico en que conste un contrato celebrado por vía electrónica será admisible en juicio como prueba documental». De este modo, nos encontramos con un artículo, el 299.2 LECiv, que sostiene que el documento electrónico será admisible en juicio según las reglas de la sana crítica (artículos 382 a 384 LECiv), y con otro, el artículo 24.2 LSSICE, que afirma que una de las manifestaciones de este documento electrónico, cual es el contrato electrónico, será también admisible en juicio, pero no como medio de prueba sujeto a las reglas de la sana crítica, sino como prueba plena derivada de su consideración como medio de prueba documental (artículos 299.1.3 y 326.2 LECiv). Por su parte, aquellos contratos electrónicos firmados electrónicamente estarán sujetos a lo dispuesto en el artículo $3 \mathrm{LFE}^{88}$ (artículo 24.1.2 ${ }^{\circ} \mathrm{LFE}$ ), concretamente a lo establecido en los apartados

\footnotetext{
${ }^{85}$ Ley 16/1985, de 25 de junio, del patrimonio histórico español (BOE núm. 155, de 29 de junio de 1985).

${ }^{86}$ Real Decreto 828/1995, de 29 de mayo, por el que se aprueba el Reglamento del impuesto sobre transmisiones patrimoniales y actos jurídicos documentados (BOE núm. 148, de 22 de junio de 1995).

${ }^{87}$ Ley Orgánica 10/1995, de 23 de noviembre, del Código penal (BOE núm. 281, de 24 de noviembre de 1995).

${ }^{88}$ Ley 59/2003, de 19 de diciembre, de firma electrónica (BOE núm. 304, de 20 de diciembre de 2003).
} 
$8^{89}$ y siguientes de dicho precepto tercero, en el que se llega a la misma conclusión, al establecer que el soporte en que se hallen los datos firmados electrónicamente (en este caso, documento electrónico en forma de contrato electrónico que consta de firma electrónica) será admisible en juicio como prueba documental, si bien establece una distinta graduación dependiendo del tipo de firma electrónica. Para resolver esta antinomia es preciso acudir al así calificado por la jurisprudencia como principio general del Derecho de especialidad normativa conocido como lex specialis derogat lei generali, que dispone que la ley especial prevalece siempre sobre la ley general, de modo que, en este caso, la LSSICE y la LFE habrá de prevalecer sobre la LECiv y, en consecuencia, el contrato electrónico específicamente (no, bien es cierto, el documento electrónico en general) habrá de tener la consideración de prueba documental en juicio, ya esté, o no, firmado electrónicamente.

Es esta misma LFE la que hace constar, por primera vez en nuestro Derecho interno, una definición de documento electrónico ${ }^{90}$, en consonancia con la teoría de la palabra que encabeza el presente apartado. En efecto, en su artículo 3.5, la LFE define el documento electrónico como «[...] la información de cualquier naturaleza en forma electrónica, archivada en un soporte electrónico según un formato determinado y susceptible de identificación y tratamiento diferenciado» ${ }^{91}$. En el soporte electrónico podrán ser archivados (artículo $3.6 \mathrm{LFE}^{92}$ ) tanto documentos electrónicos públicos (entre los cuales se encuentran los documentos públicos propiamente dichos -aquellos firmados electrónicamente por funcionarios que tengan legalmente atribuida la facultad de dar fe pública, judicial, notarial o administrativa, siempre que actúen en el ámbito de sus competencias con los requisitos exigidos por la ley en cada caso- y los documentos oficiales -aquellos expedidos y firmados electrónicamente por funcionarios 0

\footnotetext{
${ }^{89}$ El artículo 3.8 se ha visto modificado por el artículo 5.2 Ley 56/2007, de 28 de diciembre, de medidas de impulso de la sociedad de la información (BOE núm. 312, de 29 de diciembre de 2007), en adelante, LMISI.

${ }^{90}$ En relación con la regulación del documento electrónico en la UE y sus antecedentes, puede verse la obra de Díaz Fraile, J. M., "El documento electrónico y la firma digital: su regulación en la Unión Europea”, cit. 18.

${ }^{91}$ En palabras de VEGA VEGA, J. A., “La forma en el negocio jurídico electrónico”, Revista de estudios económicos y empresariales, n. 23, 2011, p. 149, «[...] el documento electrónico responde a las necesidades de las nuevas tecnologías y a la evolución del lenguaje comunicativo entre los hombres que, desde el punto de vista de la interpretación semiótica, hace que los significantes puedan ser magnitudes físicas que representan en forma codificada un mensaje o una expresión, por lo que el problema queda reducido a una representación formal de un acto jurídico por nuevos medios que la tecnología nos permite». Antes de la reforma operada por el artículo 5.1 LMISI, el documento electrónico era definido, en mi opinión erróneamente, como aquel documento «[...] redactado en soporte electrónico que incorpore datos que estén firmados electrónicamente». El error radica de vincular necesariamente al documento electrónico, para que sea tal, con la firma electrónica, ya que pueden existir perfectamente documentos de esta naturaleza (como sucede con los documentos archivados en soporte físico papel) que no se acompañen de firma, siendo igualmente válidos y eficaces aun no estando dotados de este importante instrumento probatorio.

${ }^{92}$ En mi opinión, el artículo 3.6 LFE incurre en errores de concepto, ya que el documento (sea o no de naturaleza electrónica) nunca es soporte de otros documentos. Por ello, entiendo que es más correcto decir que el soporte electrónico podrá archivar documentos electrónicos, ya sean públicos (en su doble naturaleza) como privados.
} 
empleados públicos en el ejercicio de sus funciones públicas, conforme a su legislación específica-) como documentos privados. Estos documentos tendrán el valor y eficacia que corresponda a su respectiva naturaleza, de conformidad con la legislación que les resulte aplicable (artículo 3.7 LFE).

\section{CONCLUSIONES}

A la vista de todo cuanto se ha expuesto, podemos ver cómo la conformación legal del documento, primero, y de su vertiente electrónica, más tarde, se han conformado sobre una base terminológica errónea, hasta cierto punto lógica en aquellos tiempos, cual es la identificación entre documento y escrito y entre escrito y soporte físico. Ello ha obstaculizado la apertura terminológica del concepto documento a modalidades en ese momento desconocidas pero en la actualidad tan importantes, como son aquellas propiciadas por el advenimiento de lo que en la actualidad conocemos como sociedad de la información, que ha cambiado profundamente las viejas estructuras jurídicas por medio de una adaptación del viejo sistema tradicional, primero, y de una creación de un nuevo Derecho para dar respuesta a las grandes incógnitas suscitadas por las nuevas tecnologías de la información y de la comunicación, después.

Es esta la razón que ha motivado la exclusión del documento electrónico como prueba documental en la LECiv, razón que, repetimos, deriva de antaño, de un momento en el que, por ser siempre físico y en papel, ni siquiera se imaginaba la recogida y conservación del documento en otros soportes, como el electrónico, capaces de albergar nuevos soportes y de satisfacer (y he aquí lo importante) fielmente los requisitos esenciales y las finalidades fundamentales que está llamado a desempeñar como elemento de conservación, integridad y prueba de, en lo que aquí nos interesa, los negocios comerciales llevados a cabo por las partes y plasmados en forma de contratos (electrónicos). Esta necesidad es la que ha permitido dotar a esta nueva realidad de una regulación que, hasta cierto punto contradictoria con aquella contenida en la LECiv, reconoce abiertamente la importancia del documento electrónico a efectos de prueba, determinando su papel como prueba documental en juicio. Este es el caos de la LSSICE y, cuando el contrato está dotado de firma, de la LFE.

A la vista de todo lo anterior, el presente trabajo persigue poner de manifiesto la controversia existente respecto de esta cuestión y la necesidad de conformar un nuevo término jurídico de documento que, abierto a la nueva realidad virtual que cada vez se presenta con mayor fuerza, incluye una propuesta de lege ferenda. Esta propuesta perseguirá, al mismo tiempo, conseguir la tan anhelada coherencia normativa y evitar alejarse de la misión que el documento está llamado a cumplir en el Derecho procesal interno de nuestro país desde hace ya tanto tiempo. Sólo así podremos afrontar de manera satisfactoria los importantes retos que el futuro legal nos depara. 


\section{BIBLIOGRAFÍA}

Adsuara VARela, B., "Algunas consideraciones previas sobre el comercio electrónico”, Información comercial española, n. 813, 2004, p. 15 a 26.

Almagro Nosete, J., Derecho procesal, Tirant lo Blanch, Valencia, 1996.

Álvarez SAAvedra, F. J., Diccionario de criminalística. Los secretos de las investigaciones de la policía científica, Planeta, Barcelona, 2003.

AmAR RoDRíguez, V. M., "La interculturalidad tecnológica: inforricos e infopobres", en Inmigración, interculturalidad y convivencia, Instituto de Estudios Ceutíes, Ceuta, 2002, p. 363 a 370.

ARIAs POU, M., Manual práctico de comercio electrónico, La Ley, Las Rozas, 2006.

Asencio Mellado, J. M., Derecho procesal civil, Tirant lo Blanch, Valencia, 2015.

BARIATTI, S., "Internet: aspects rélatifs aux conflits de lois", Rivista di Diritto internazionale privato e processuale, n. 550, 1997, p. 545 a 556.

BARLOW, J. P., "A declaration of the independence of cyberspace”, 1996, Davos.

BARNES VÁzQUEZ, J., "La Internet y el Derecho: una nota acerca de la libertad de expresión e información en el espacio cibernético”, Cuadernos de Derecho judicial, n. 6, 1997, p. 235 a 241.

BENTHAM, J., Rationale of judicial evidence: specially applied to English practice, Manuscrito, Londres, 1827.

Botana García, G. A., Comercio electrónico y protección de los consumidores, Wolters Kluwer, Las Rozas, 2001.

Bowrey, K., Law \& Internet cultures, Cambridge University Press, Cambridge, 2005.

Bravo, F., Contrattazione telematica e contrattazione cibernetica, Giuffrè, Milán, 2007.

BURNSTEIN, M. R., "Conflicts on the net: choice of Law in transactional cyberspace", Vanderbilt journal of transactional Law, n. 29, 1996, p. 75 a 90.

Cabanellas de las Cuevas, G., Derecho de Internet, Elisa, Buenos Aires, 2012.

Calvo Caravaca, A.; Carrascosa González, J., Conflictos de leyes y conflictos de jurisdicción en Internet, Colex, Madrid, 2001.

CARnElutTI, F., La prova civile: parte generale. Il concetto giuridico della prova, Giuffrè, Milán, 1992.

CARRASCOSA LÓPEZ, V., "Valor probatorio del documento electrónico”, Informática y Derecho: revista iberoamericana de Derecho informático, n. 8, 1995, p. 133 a 174.

CARretero PÉrez, J., Descubre Internet, Prentice Hall, Madrid, 2001.

CASTElls Oliván, M., The power of identity, Wiley-Blackwell, Oxford, 2010.

CAVANILlas MúGICA, S., "Dieciocho recomendaciones para la empresa que practique comercio electrónico con consumidores”, Actualidad informática Aranzadi: revista de informática para juristas, n. 37, 2000, p. 1 a 6.

CREMAdes GarcíA, J.; GONZÁlez Montes, J. L., La nueva Ley de Internet: comentarios a la Ley 34/2002, de 11 de julio, de Servicios de la Sociedad de la Información y de Comercio Electrónico, La Ley-Actualidad, Las Rozas, 2003.

De la Oliva Santos, A., Derecho procesal civil, Centro de estudios Ramón Areces, Madrid, 1995. 
De Miguel Asensio, P. A., Contratación electrónica, Aranzadi, Cizur Menor, 2015.

De Miguel Asensio, P. A., Derecho privado de Internet, Civitas, Madrid, 2001.

Delacourt, J. T., “The international impact of Internet regulation", Harvard international law journal, n. 38, 1997, p. 207 a 235.

DEVIS EchandíA, H., Teoría general de la prueba judicial, Zavalía, Buenos Aires, 1970.

Di Cocco, C.; Sartor, G., Temi di Diritto dell'informatica, Giappichelli, Turín, 2013.

Díaz Fraile, J. M., "El comercio electrónico: Directiva y Proyecto de Ley español de 2000. Crónica de su contenido, origen, propósitos y proceso de elaboración”, Actualidad civil, n. 1, 2001, p. 31 a 58.

DíAz FrAILE, J. M., "El documento electrónico y la firma digital: su regulación en la Unión Europea”, Noticias de la Unión Europea, n. 177, 1999, p. 9 a 30.

Elías BAtURones, J. J., La prueba de documentos electrónicos en los tribunales de justicia, Tirant lo Blanch, Valencia, 2008.

Elosua De JuAn, M., Diccionario LID. Comunicación y marketing, Lid, Madrid, 2004.

FERNÁNDEZ EsTEBAN, M. L., "Limitaciones constitucionales e inconstitucionales a la libertad de expresión en Internet”, Revista española de Derecho constitucional, n. 53, 1998, p. 283 a 311.

Finocchiaro, G. D.; Delfini, F., Diritto dell'informatica, Utet Giuridica, Milanofiori Assago, 2007.

GARCÍA DE ENTERRÍA MARTínez-CARANDE, E., Justicia y seguridad jurídica en un mundo de leyes desbocadas, Civitas, Madrid, 1999.

Gautrais, V.; Lefebvre, G.; BenyeKhlef, K., "Droit du commerce électronique et normes applicables: l'emergence de la lex electronica”, Revue de Droit des affaires internationales, n. 5, 1997, p. 547 a 583.

GIBSON, W., Johnny Mnemonic, Ace Books, Nueva York, 1982.

GIBSON, W., Neuromancer, Ace Books, Nueva York, 1984.

GigANTE, A., "Blackhole in cyberspace: the legal void in the Internet", The John Marshall journal of computer \& information Law, n. 3, 1997, p. 413 a 436.

GÓMEZ DE LiAÑo GONZÁLEZ, F., El proceso civil, Forum, Oviedo, 1990.

GonZÁlez Granda, P., "Protección judicial de consumidores y usuarios en el ámbito del comercio electrónico”, Indret: revista para el análisis del Derecho, n. 4, 2007, p. 1 a 36.

GoulD, M., "Rules in the virtual society”, International review of Law, computers \& technology, n. 2, 1996, p. 199 a 218.

GuERRERo ClAVIJO, R., "Novedades en materia de contratación mercantil introducidas por la Ley de Servicios de la Sociedad de la Información”, CEFLegal: revista práctica de derecho. Comentarios y casos prácticos, n. 47, 2004, p. 3 a 28.

JimÉNEZ DE PARGA CABRERA, R., “El comercio electrónico ¿¿seguridad jurídica?”, Derecho de los negocios, n. 118 y 119, 2000, p. 1 a 12.

Joly-PASSAnt, E., L'écrit confronté aux nouvelles technologies, Lgdj, París, 2006.

LEMLEY, M. A.; LESSIG, L., The end of end-to-end: preserving the architecture of the Internet in the broadband, Ucla Law Review, Los Ángeles, 2000.

LÉVY, P., Qu'est-ce que le virtuel?, La Découverte, París, 1998.

LÓPEZ RichART, J., "Difamación en la web 2.0 y responsabilidad civil de los 
prestadores de servicios de alojamiento”, Derecho privado y Constitución, n. 26, 2012, p. 143 a 201.

LorenzetTi, R., Comercio electrónico: documento, firma digital, contratos, daños, defensa del consumidor, Abeledo-Perrot, Buenos Aires, 2001.

MADRID PARRA, A., "Contratación electrónica”, en Estudios jurídicos en homenaje al profesor Aurelio Menéndez, Civitas, Madrid, 1996.

MAestri, E., Lex informatica: Diritto, persona e potere nell'età del cyberspazio, Edizioni Scientifique Italiane, Nápoles, 2015.

MARTínez NADAL, A., "Comercio electrónico”, en Curso sobre protección jurídica de los consumidores, McGraw-Hill, Madrid, 1999.

MARTínez NADAL, A., "La protección del consumidor en la propuesta de directiva sobre determinados aspectos del comercio electrónico", Cuadernos de Derecho y comercio, n. 29, 1999, p. 111 a 156.

Menéndez Mato, J. C.; Gayo Santa Cecilia, M. E., Derecho e informática: ética y legislación, Bosch, Vallirana, 2014.

Miranda Serrano, L. M.; Vela Torres, P. J.; Príes Picardo, A., La contratación mercantil. Disposiciones generales. Protección de los consumidores, Marcial Pons, Madrid, 2006.

Moliní FERnÁNDEZ, F., "Ventajas, inconvenientes e impactos territoriales del comercio electrónico”, Investigaciones geográficas, n. 27, 2002, p. 131 a 150.

Montero Aroca, J., La prueba en el proceso civil, Civitas, Madrid, 2001.

MuÑOz MACHADO, S., La regulación de la Red: poder y Derecho en Internet, Taurus, Barcelona, 2000.

NESPOR, S.; CESARIS, A. L., Internet e la legge: la persona, la proprietà intellettuale, il commercio elettronico, gli aspetti penalistici, Hoepli, Milán, 2001.

Olivencia Ruiz, M., "De nuevo la Lección 1. a . Sobre el concepto de la asignatura. Discurso leído en la solemne apertura del curso académico”, 1999, Universidad de Sevilla.

Ortiz Navacerrada, S., La prueba de documentos en el proceso civil: estudio jurisprudencial, Actualidad, Alcobendas, 1994.

PANEBIANCO, M., Introduzione al Diritto comunitario comparato: Diritto internazionale e Diritto dell'integrazione nell'Europa comunitaria e in America Latina, Edisud, Aix-en-Provence, 1985.

PASCUZZI, G., Il Diritto dell'era digitale, Il Mulino, Bolonia, 2006.

Peguera Poch, M., Principios de Derecho de la sociedad de la información, Aranzadi, Cizur Menor, 2010.

PÉrez Bes, F., El Derecho de Internet, Atelier, Barcelona, 2016.

Plaza Penadés, J., Derecho y Nuevas Tecnologías de la Información y la Comunicación, Aranzadi, Cizur Menor, 2013.

Plaza PenadÉs, J., Propiedad intelectual y sociedad de la información: Tratados OMPI, Directiva 2001/29/CE y responsabilidad civil en la Red, Aranzadi, Cizur Menor, 2002.

RAMOS MÉNDEZ, F., Enjuiciamiento civil, Bosch, Barcelona, 1997.

Real Academia Española, Definiciones de documento, escribir, letra, signo, dato y soporte, 2017. 
REIDENBERG, J. R., "Lex informatica: the formulation of information policy rules through technology", Texas Law review, n. 3, 1998, p. 553 a 593.

Rosello, C., Commercio elettronico: la governance di Internet tra Diritto statuale, autodisciplina, soft Law e lex mercatoria, Giuffrè, Milán, 2006.

SÁBADA CHALEZQUER, C., "Interactividad y comunidades virtuales en el entorno de la world wide web”, Comunicación y sociedad, n. 1, 2000, p. 139 a 166.

SANChís CRespo, C.; ChAVEli DONET, E. A., La prueba por medios audiovisuales $e$ instrumentos de archivo en la LEC 1/2000: doctrina, jurisprudencia y formularios, Tirant lo Blanch, Valencia, 2002.

SANJURJo ReBollo, B., Manual de Internet y redes sociales: una mirada legal al nuevo panorama de las comunicaciones en la Red, con especial referencia al periodismo digital, propiedad intelectual, protección de datos, negocios audiovisuales, ecommerce, consumidores, marketing, Dykinson, Madrid, 2015.

SARTOR, G., L'informatica giuridica e le tecnologie dell'informazione: corso d’informatica giuridica, Giappichelli, Turín, 2012.

Sentís Melendo, S., La prueba: los grandes temas del Derecho probatorio, Ejea, Buenos Aires, 1979.

SerRA Domínguez, M., "La prueba documental”, en Instituciones del nuevo proceso civil. Comentarios sistemáticos a la Ley 1/2000, Dijusa, Madrid, 2000.

Shaw, M.; Blanning, R.; Strader, T.; Whinston, A., Handbook on Electronic Commerce, Springer, Berlín, 2000.

STOLL, P. T.; GOLLER, B., Electronic commerce and the Internet, German Yearbook of International Law, Berlín, 1998.

TROTTER HARDY, I., “The proper legal regime for 'cyberspace”, University of Pittsburgh Law Review, n. 55, 1994, p. 993 a 1055.

Vega Vega, J. A., Contratos electrónicos y protección de los consumidores, Reus, Madrid.

VegA VeGA, J. A., "La forma en el negocio jurídico electrónico”, Revista de estudios económicos y empresariales, n. 23, 2011, p. 125 a 163. 